\title{
"El fantasma de la fuerza motriz del agua": Emil Rathenau y sus redes eléctricas en Chile y España
}

\author{
DOSSIER PATRIMONIO DELL'ELETTRICITÀ: CITTÀ E PAESAGGI ELETTRICI
}

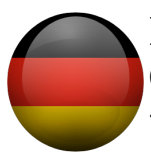
Marion Steiner

Geógrafa. Universidad Bauhaus de Weimar y Asociación Regional del Ruhr. Berlín [Berlín] Alemania <steiner@rhondda.de>.

Este artículo se publicó primero, con menos imágenes, en: Zaar, M. H., Vasconcelos P. Jr., M., \& Capel, H. (Eds.) (2017). La electricidad y el territorio. Historia y futuro. Barcelona: Universidad de Barcelona/Geocrítica, $<\mathrm{http://www.ub.edu/geocrit/Electr-y-territorio/Electr-y-territorio-Portada.htm>.} \mathrm{ISBN:} \mathrm{978-84-697-6835-8}$

\section{Resumen}

En 1902, el fundador de la AEG berlinesa, Emil Rathenau, llamó a la fuerza motriz del agua "un fantasma ... que ha completado su vuelta por el mundo". En ese entonces, la gran mayoría de los sistemas eléctricos construidos por su empresa se basaban en el uso de carbón y, en España, sus centrales térmicas ya suministraban energía a gran parte de las ciudades. En Chile, por el contrario, debido a contratos firmados con las Municipalidades de Santiago y Valparaíso en 1898 y 1902 respectivamente, la AEG se vió obligada a instalar sistemas hidroeléctricos. El presente artículo reconstruye las disputas respectivas entre empresa y municipalidad sobre el uso de la fuerza hidráulica en Santiago y las contrasta con la situación en Cataluña, España. Ambos casos se contextualizan desde una perspectiva global de análisis geopolítico lo cual permite explicar además la red mundial de actores involucrados y las estrategias implementadas por las empresas eléctricas y bancos alemanes para conquistar el mercado mundial, hasta un poco más allá de la Primera Guerra Mundial.

\section{Palabras clave}

Electrificación temprana. Elektropolis Berlin. Imperio alemán. Análisis geopolítico. Red mundial de actores. Termo versus hidroelectricidad.

\section{"The ghost of the water's power": Emil Rathenau and his electrical networks in Chile and Spain}

\begin{abstract}
In 1902, the founder of AEG in Berlin, Emil Rathenau, called water power a "ghost [...] that has completed his tour around the world." The vast majority of electrical systems his company had built at that time were based on the use of coal and, in Spain, its thermal power plants already supplied much of the cities. In Chile, on the contrary, according to contracts signed with the municipalities of Santiago and Valparaiso in 1898 and 1902, AEG was obliged to install hydroelectric systems. This article re-constructs the corresponding disputes between the company and the municipality on the use of hydraulic force in Santiago and contrasts them with the situation in Catalonia. Both cases are contextualized from a global perspective of geopolitical analysis that allows for also explaining the global network of actors involved and the strategies implemented by German electric companies and banks to conquer the world market, up to a little beyond the end of World War I.
\end{abstract}

\section{Keywords}

Early electrification. Elektropolis Berlin. German empire. Geopolitical analysis. Global networks of power. Thermo versus hydroelectricity. 


\section{Introducción}

Al finalizar el siglo XIX, el Imperio Alemán, recién unificado en 1871, y los Estados Unidos de América - ambos protagonistas de la innovación tecnológica en el sector de la electricidad - desafiaron a Inglaterra como potencia mundial hegemónica. Cuatro grandes empresas ya habían adquirido una posición dominante en el mercado eléctrico mundial de aquel momento: en EE.UU. la General Electric de Thomas A. Edison y la Westinghouse; y en Alemania la Allgemeine ElektricitätsGesellschaft (AEG) y Siemens \& Halske, ambas con sede en Berlín.

La capital alemana, iniciando su fama como Elektropolis ${ }^{1}$, servía como base de operación a los principales actores alemanes del negocio eléctrico mundial, y en el centro de la ciudad trabajaban un triángulo característico de inventores, empresarios y financieros. Entre ellos, destacan como personalidades más importantes: Werner Siemens (1816-1892), el inventor del dínamo y del motor eléctrico, quien, junto a Johann Georg Halske, en el año 1847 fundó la Telegraphen BauAnstalt von Siemens \& Halske in Berlin e inicialmente conquistó el mercado con tecnologías de corriente de bajo voltaje como la telegrafía y la radio; Emil Rathenau (1838-1915), quien en 1882 después de diez años de fracasos profesionales se hizo con los patentes de Edison para Alemania y en 1883 fundó la Deutsche Edison Gesellschaft, la cual fue reconvertida en la AEG en 1887; y Georg Siemens (1839-1901), uno de los directores fundadores del Deutsche Bank en 1870, quien previamente ya había demostrado sus habilidades diplomáticas en Persia en la construcción de la línea telegráfica Londres-Teherán-Calcuta realizada por la compañía de su tío Werner anteriormente mencionado.

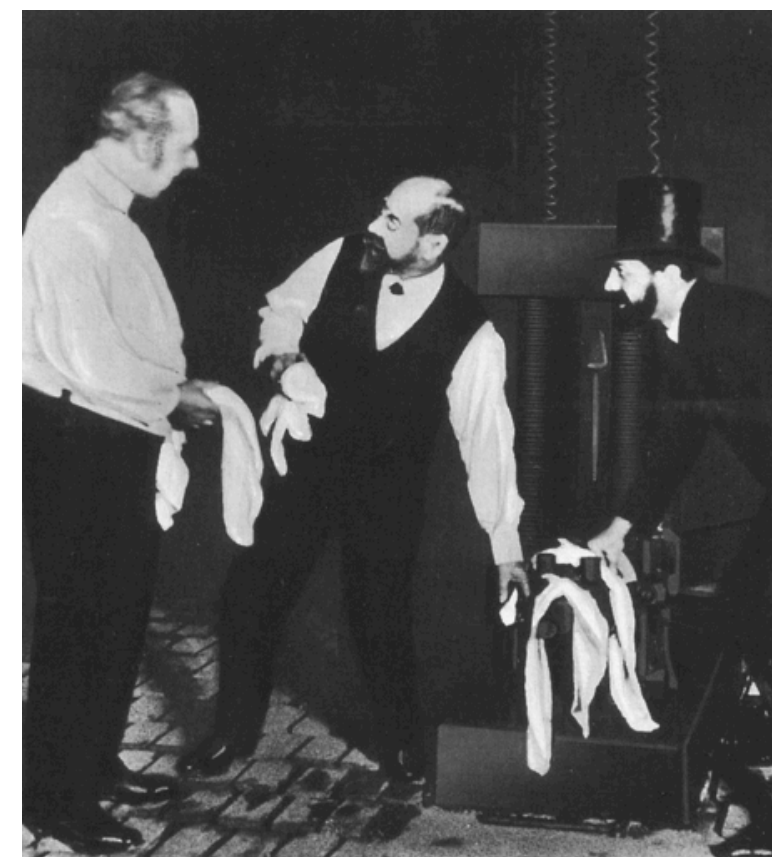

Figura 1: Emil Rathenau (1838-1915) en una muestra del alumbrado eléctrico en 1882 en el noble restaurante "Ressource" de Berlín. Fuente: Archivo BEWAG, Vattenfall Europe, Berlín.
Mientras que la AEG ya había nacido como sociedad anónima y actuaba en el mercado financiero internacional desde muy temprano, la empresa familiar Siemens \& Halske se negó, durante mucho tiempo, a dar un paso parecido. Aunque Georg Siemens instó a su tío desde principios de los años 1880 para transformar su empresa en corporación anónima, Werner Siemens luchó firmemente contra esta conversión, la cual sólo se realizó en 1897, cinco años después de su muerte, cuando la política financiera de la casa Siemens había cambiado. En ese momento, el Deutsche Bank se separó, también por motivos familiares, de la AEG, a la cual había apoyado fuertemente desde 1887, transformándose ahora en el banco aliado de Siemens \& Halske. Mantuvo, sin embargo, el liderazgo en el sindicato bancario de la $\mathrm{AEG}^{2}$.

Tanto Georg Siemens como Emil Rathenau, son considerados como nuevo tipo de actores en la historia bancaria y empresarial, respectivamente. Siemens se caracteriza como el primer 'manager de bancos' (Bankmanager) en la historia de Alemania: con la Ley de las Sociedades Anónimas modificada en 1884, que amplió considerablemente los poderes de los directores de bancos, el director del Deutsche Bank se puso a promover y dirigir proactivamente los negocios internacionales de muchas empresas industriales alemanas. A Rathenau, por su parte, se considera el primer 'manager de empresas' (Unternehmensmanager): "reconoció la curiosidad y la comodidad de los consumidores, cuya necesidad por las innovaciones sólo tenía que ser despertada". Inventó el marketing corporativo moderno y encargó a Peter Behrens el desarrollo de un diseño gráfico homogéneo para la $\mathrm{AEG}$, lo cual el más viejo y más

1 Véase, entre otros, Dame 2011, 14-35 y Steiner 2013.

2 Pohl 1988, 117-128, 141; Gall 1995, 38.

(c) Labor \& Engenho, Campinas [SP] Brasil, v.11, n.4, p.446-476, out./dez. 2017. 
tradicional Werner Siemens criticó como competencia desleal y un verdadero "escándalo". Para él, fue difícil hacerse a la idea de que ya no fuera solamente la calidad tecnológica e ingenieril la que convenciera a los clientes de comprar los nuevos productos, sino que además fuese necesario implementar también estrategias de comunicación para conquistar con éxito los mercados. ${ }^{3}$

Dentro de esta constelación básica de los global players alemanes en el negocio eléctrico mundial, el presente artículo se centra en el grupo de actores asociados a la AEG y las redes de Emil Rathenau en España y Chile; desde el inicio de sus negocios eléctricos en el extranjero hasta un poco más allá del término de la Primera Guerra Mundial ${ }^{4}$.

\section{La AEG y sus redes eléctricas en España}

La primera ciudad fuera de Alemania para la cual la AEG estableció una empresa operadora eléctrica fue la capital española, Madrid. Aquí, la AEG aunó fuerzas con la empresa instaladora Levi \& Kocherthaler, la cual ya tenía una concesión para construir una central eléctrica, y juntos formaron la Compañía General Madrileña de Electricidad en 1889 con un capital inicial registrado de 3 millones de pesetas, de los

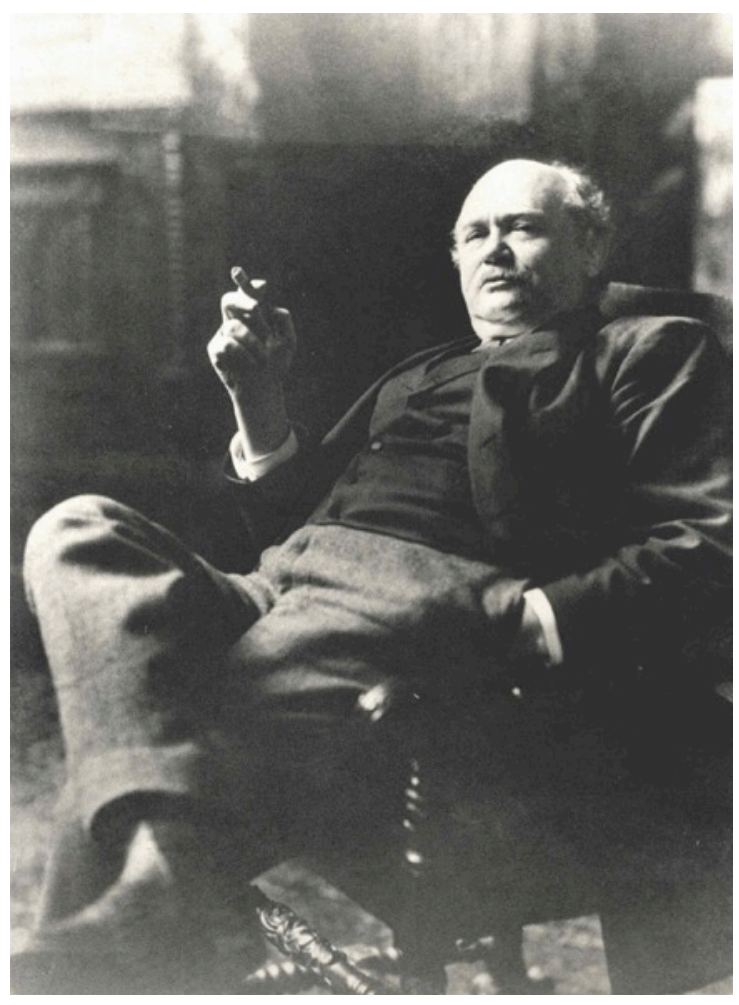

Figura 2: Georg Siemens (1839-1901), director del Deutsche Bank, alrededor de 1895. Fuente: Instituto Histórico del Deutsche Bank, Frankfurt am Main. cuales la AEG reunió la mitad. Este principio de formar una empresa operadora que, a su vez, contrate a la misma empresa fabricante que participó en su creación para que construyera las instalaciones, es típico de lo que ya en aquel momento se llamaba Unternehmergeschäft (negocio empresario) en Alemania5.

La empresa Levi y Kocherthaler resultó ser un socio fiable para la AEG y, gracias a sus buenas relaciones de negocios, la AEG recibió pedidos para construir centrales eléctricas en otras 12 ciudades españolas a partir de 1890, rápidamente. En 1898, ya había construido centrales en 36 ciudades y pueblos españoles, lo cual representa el mayor número de centrales eléctricas construidas por la AEG en un solo país fuera del Imperio Alemán. España fue seguida por Italia, donde la AEG solo construyó 15 centrales. Paralelamente la AEG siguió fundando en España más empresas operadoras; por ejemplo el 23 de julio de 1894, la Compañía Sevillana de Electricidad; el 7 de diciembre de 1894, la Compañía Barcelonesa de Electricidad; y a finales de 1896, la Compañía de Electricidad Vizcaína en Bilbao, la capital del país Vasco el cual fue la segunda región industrial más importante de España detrás de Cataluña. A diferencia de las inversiones británicas y francesas en España, la fundación de empresas alemanas se realizó bajo la legislación española y con sede y nombre español. Otra táctica que también resultó ser beneficiosa fue la de nombrar Presidente de la Junta a un compatriota del país en el que la empresa debía operar. ${ }^{6}$

Sobre la base de las buenas relaciones de su socio Levi \& Kocherthaler y con la ayuda de sus potentes inversores, en tan sólo cinco años la AEG adquirió "una posición dominante en la electrificación de España", según señala el historiador del Deutsche Bank Manfred Pohl. Esta posición se

3 Gall 1995, 14, 119; Pohl 1988, 17, 117-119, 203.

${ }^{4}$ Mis interpretaciones se basan en las investigaciones que he llevado a cabo entre 2013 y 2015 en diversos archivos y bibliotecas en Chile y Alemania para mi tesis doctoral: "El enchufe chileno. Un análisis geopolítico de la electrificación alemana en Valparaíso y Santiago, 1880-1925".

5 Para más explicaciones sobre el Unternehmergeschäft véase por ejemplo Hertner 2013, 92 y Pohl 1988, 17.

6 Gwinner 1926, 57; Loscertales 2002, 149-201; Pohl 1988, 105-106, 148, 150; las actividades de la AEG en España, y particularmente en Cataluña, véase además Capel 1994, vols. 1 y 2

(c) Labor \& Engenho, Campinas [SP] Brasil, v.11, n.4, p.446-476, out./dez. 2017. 
basaba también en el uso inteligente de la publicidad, lo cual la empresa ya había probado con éxito en Alemania. Ofertaba, por ejemplo, primero en Barcelona, instalaciones gratis para consumidores potenciales con el fin de proporcionar un incentivo para la electrificación y despertar la demanda. ${ }^{7}$

Otro socio importante para las operaciones españolas de la AEG y el Deutsche Bank, aparte de Levi y Kocherthaler, era el banquero privado de nacionalidad alemana Arthur Gwinner (1856-1931). Fue él quien intervino para que la Madrileña obtuviese la concesión, ayudado por el hecho de conocer personalmente al alcalde de Madrid Cayetano Sánchez Bustillo. Sánchez fue miembro del partido conservador y en ese entonces era senador. Desde 1880 hasta 1889 fue Ministro de Ultramar y en 1890 fue nombrado Gobernador del Banco de España. Además fue miembro del Consejo de Administración del Banco Hispano Alemán que Gwinner fundó junto al Deutsche Bank en el mismo año 1889, con el fin de financiar el alumbrado público de Madrid que había ganado en concesión el grupo alemán AEG. Huelga decir que en este tipo de negocios, la corrupción y el soborno deben haber desempeñado un papel importante. Muy poco después, y como una consecuencia lógica, Gwinner fue invitado por Georg Siemens y Emil Rathenau a formar parte de la Junta de la nueva em-

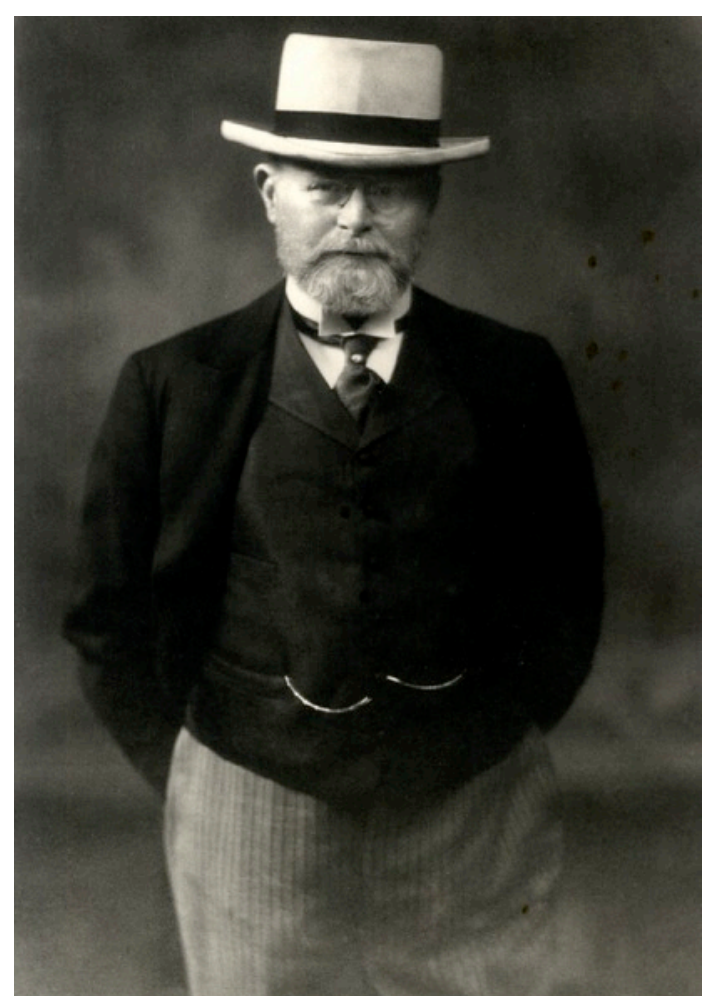

Figura 3: Arthur Gwinner (1856-1931), alrededor de 1900. Fuente: Instituto Histórico del Deutsche Bank, Frankfurt am Main. presa operadora de Madrid. Fue Gwinner quien redactó los estatutos de la Madrileña que después sirvieron a la AEG como un modelo para otras muchas empresas operadoras creadas por ella a partir de entonces en el mundo. Gwinner además, representando a los inversores alemanes, viajaba frecuentemente a España por los negocios de la Madrileña. ${ }^{8}$

Arthur Gwinner fue descendiente de una conocida familia de abogados de Frankfurt am Main. Después de un aprendizaje en un banco en su ciudad natal, se trasladó a Londres donde trabajó durante casi cuatro años en un banco de prestigio al cual había logrado ingresar gracias a las buenas relaciones de sus padres. Posteriormente, vivió durante más de seis años en Madrid, donde rápidamente adquirió una reputación como banquero, diplomático y cosmopolita. Tres años después de su llegada a Madrid, a la edad de 27 años, fue nombrado Cónsul del Imperio Alemán, y en el mismo año, 1883, compró la Torre de las Damas en la Alhambra9. Poseía también "excelentes contactos con los círculos bancarios británicos y estadounidenses" - por su propia estadía en Londres, pero también debido a su boda en octubre de 1885 con Anna Speyer, hija de la conocida familia del banco privado Lazard Speyer-Ellissen de Frankfurt am Main. Entre 1887 y 1888, Gwinner con su esposa e hijos se trasladaron desde Madrid a Berlín, la emergente capital del Imperio Alemán que pronto iba a sobrepasar a Frankfurt como la metrópolis económica y financiera líder en Alemania. Recién llegado a Berlín, Arthur Gwinner adquirió la casa bancaria Riess \& Itzinger, cuyas actividades continuó bajo su propio nombre. Poco después comenzó a colaborar, de la forma ya explicada, con la AEG y el Deutsche Bank en sus negocios eléctricos en Madrid10.

\footnotetext{
7 Pohl 1988, 150.

${ }^{8}$ Gwinner 1926, 57; Loscertales 2002, 121, 122, 152; Pohl 1988, 105; https://www.db.com/spain/es/content/HistoriaDeutsche-Bank-España.html [accedido 14.1.2017].

${ }^{9}$ En 1891, Gwinner obsequió la Torre de las Damas al Estado español y se llevó el techo interior del mirador a Berlín. Primero, la cúpula adornaba una sala oriental en su departamento en la Rauchstraße 1, y en 1928 se trasladó a su casa en la Sophienstraße 25 en Charlottenburg. Hoy en día está expuesta al público en el Pergamonmuseum. (Gwinner 1926, 45; McSweeney 2015, 89-102).

10 Historische Gesellschaft der Deutschen Bank e.V. (Sociedad Histórica de la Deutsche Bank, citada en adelante como HGDB). Arthur von Gwinner. www.bankgeschichte.de/de/content/858.html [accedido 28.2.2016]; Gwinner 1926, 32,
} 36-38, 41-45, 53; Gall 1995, 8, 93-94. 
En septiembre de 1893 se le preguntó oficialmente a Gwinner si quería ser el sucesor de Hermann Wallich (1833-1928) y colega de Georg Siemens en el directorio del Deutsche Bank. Habían sido decisivos para esta oferta los encuentros personales con Georg Siemens y Hermann Wallich en algunos viajes en tren entre Madrid y Berlín, que Gwinner relató de manera anecdótica en el año 1926 en sus memorias. En 1894, Gwinner ingresó al Consejo de Administración de Deutsche Bank, y en el mismo año vendió su parte del Banco Hispano Alemán y liquidó su banco privado en Berlín11.

Por su parte en el año 1894, la AEG también vende obteniendo buenas ganancias sus acciones en la Madrileña. La venta efectuada a unos inversores franceses fue gestionada nuevamente por Arthur Gwinner ${ }^{12}$. El ejemplo demuestra, entre otras cosas, que el principal interés de la AEG no se basaba en gestionar a largo plazo el suministro eléctrico, más bien se trataba de embolsarse las ganancias logradas con la construcción de las instalaciones y tan pronto como fuera posible, después de su puesta en servicio, vender las acciones de las empresas operadoras para suministrarle al nuevo operador y durante un largo plazo, material de alta tecnología y know-how. Madrid no fue una excepción a esta norma. Al mismo tiempo, esta lógica capitalista significa que el fabricante no poseía verdadero interés en planificar y construir sistemas de suministro eléctricos que se adaptaran bien a las condiciones locales, y que fuesen beneficiosas y sostenibles a largo plazo.

El giro profesional de Gwinner desde el sector de los bancos privados para entrar en el directorio del Deutsche Bank, refleja por un lado la política estratégica de recursos humanos que manejaban los grandes bancos de acciones alemanes. Para llevar a cabo exitosamente su ambición de conquistar el mercado mundial fue de crucial importancia contratar a personal calificado que, de preferencia, contara con muchos años de experiencia en el negocio financiero internacional y habilidades diplomáticas comprobadas y que además dispusiera de valiosas redes de contactos internacionales y supiese negociar en varios idiomas. Por otro lado, la integración de Gwinner en el directorio del Deutsche Bank refleja el auge de los grandes bancos alemanes que en aquellos momentos alcanzaron una posición de supremacía frente a las empresas privadas que hasta ese entonces habían dominado el sector bancario. El cambio tecnológico que se produjo hacia finales del siglo XIX fue decisivo en este contexto, ya que implicaba la construcción de nuevos sistemas e infraestructuras de una escala cada vez más grande, y los bancos de acciones contaban con mayores facilidades que los pequeños bancos privados a la hora de financiar las obras de tal envergadura, especialmente en el sector electrotécnico. Gwinner, muy tempranamente, se había dado cuenta de estas nuevas tendencias en el mercado y actuaba de acuerdo con las consecuencias.

Su entrada en el Deutsche Bank, dio además frutos respecto a su posición social. Cuando a finales del 1900, por razones de salud, Georg Siemens renunció a la junta falleciendo poco más tarde a la edad de solo 62 años, Arthur Gwinner se hizo cargo de sus responsabilidades - sobre todo de "las grandes operaciones internacionales, como el ferrocarril de Bagdad y la financiación del ferrocarril en América del Norte," y del negocio del petróleo del Deutsche Bank. Su nombre está además "estrechamente relacionado con el desarrollo del negocio internacional de la industria de la ingeniería eléctrica." Todos estos negocios fueron actividades tanto económicas como también políticas y requerían mucha habilidad diplomática. En poco tiempo, Arthur Gwinner adquirió una reputación como "el diplomático del banco", una tarea para la cual "fue particularmente bien calificado por sus características cosmopolitas y sus excelentes habilidades lingüísticas", según puso de manifiesto la Sociedad Histórica del Deutsche Bank en una de sus reseñas biográficas. En estos proyectos, Gwinner estableció numerosos contactos personales y de prestigio, por ejemplo con el embajador alemán en Turquía, el Baron von Marschall Bieberstein, quien en invierno de 1908 velaba por su ennoblecimiento. Conocía también muy bien al Canciller von Bülow al cual debía, entre otras cosas, su nombramiento como miembro de la Cámara Alta de Prusia el día 27 de enero de 1910. Si bien no fue el primer banquero en ingresar a la Cámara Alta de Prusia, sí fue el primer director de un banco de acciones en hacerlo. La Cámara en ese entonces estaba compuesta por unos 300 miembros, de los cuales cinco eran banqueros. 13

\footnotetext{
11 HGDB op. cit; Gwinner 1926, 54, 55, 57, 58-59; Loscertales 2002, 122-123, 155.

12 Pohl 1988, 106; Gwinner 1926, 58.

13 HGDB op. cit; Gall 1995, 16, 94, 96; Gwinner 1926, 106.
} 


\section{Estrategias para conquistar el mercado sudamericano}

La gran importancia que tenía España para los negocios eléctricos de la AEG y del Deutsche Bank tal vez nos sorprenda hoy en día, al menos desde la perspectiva alemana. No obstante, ya en aquella época, los bancos y también las empresas alemanas percibían a este país en el suroeste del continente europeo como un trampolín hacia América del Sur. Este continente distante fue considerado en aquel entonces económicamente emergente y sus mercados representaron un gran atractivo. Como parte de una estrategia general para conquistar los "mercados de ultramar", en las dos últimas décadas del siglo XIX, muchos de los principales bancos de acciones alemanes establecieron subsidiarias y filiales responsables cada una de un país o región.

Como sociedad filial al 100 por ciento del Deutsche Bank se creó, por ejemplo, el Deutsche Ueberseeische Bank (DUB), destinado a conquistar el mercado de América del Sur. Abrió su primera filial en Buenos Aires bajo el nombre de Banco Alemán Transatlántico (BAT) el 5 de agosto de 1887, y la segunda en febrero de 1896 en la ciudad portuaria chilena de Valparaíso, del lado pacífico del continente, que fue seguida un año después por una filial en la capital del país, Santiago. El 7 de marzo de 1904 empezó a funcionar en la ciudad portuaria catalana de Barcelona la primera filial del BAT en España cuya misión consistía, más allá de establecer relaciones comerciales con España, en promover los negocios en América del Sur. En 1907 fue seguido por una filial del BAT en la capital española, Madrid14. Es interesante observar como en los dos países, los bancos alemanes entraron por los puertos para luego establecer filiales también en las ciudades sede del gobierno nacional, donde empezaron a ejercer una cierta influencia sobre las políticas económicas de los estados a cuyos mercados estaban atacando.

También la Disconto-Gesellschaft de Berlín, la cual había sido el instituto financiero líder en Alemania hasta que fue superado en 1876 por el Deutsche Bank, creó subsidiarias para América del Sur. Primero fundó, en 1887, el Banco Brasileño para Alemania, junto con un banco de acciones afiliado de Hamburgo, el Norddeutsche Bank in Hamburg (NDB), el cual según Lothar Gall, otro historiador del Deutsche Bank, se dedicaba sobre todo a la financiación de los negocios en el extranjero, teniendo "intereses ampliamente ramificados en América del Sur". Luego, en 1895, fundaron, otra vez juntos, el Banco de Chile y Alemania que abrió su primera filial en Valparaíso en el mismo mes que empezó a funcionar también la filial del BAT en Valparaíso, el centro comercial y financiero de Chile. El hecho de que los dos bancos de acciones más importantes de Alemania abrieran oficinas en Chile casi simultáneamente demuestra lo grande que pensaban que era el potencial económico de este país. 15

Al igual que los bancos, las empresas de ingeniería eléctrica también buscaron activamente conquistar el mercado sudamericano. En enero de 1898 se fundó en Berlín la Deutsche Ueberseeische Elektricitäts-Gesellschaft (DUEG), la cual fue conocida en Iberoamérica por el nombre de Compañía Alemana Transatlántica de Electricidad (CATE). La dirección de su sindicato fue llevado desde sus inicios por el Deutsche Bank y las posiciones más altas según un principio llamado Personalunionen en alemán, que debía garantizar que los negocios respectivos se desarrollasen con "objetivos sincrónicos", las ocupaban siempre las mismas personas. Arthur Gwinner, por ejemplo, durante muchos años fue a la vez miembro de la Junta del Deutsche Bank y presidente del Consejo de supervisión de la DUEG/CATE.

Habiendo empezado como empresa operadora para Buenos Aires, la DUEG/CATE pronto se convirtió en un holding para los negocios eléctricos en todo el continente, lo cual varios historiadores sospechan se encontraba planificado desde el principio. En 1905 y 1906, respectivamente, la CATE se hizo cargo de las empresas operadoras de las dos principales ciudades de Chile en cuya fundación la AEG había participado de manera decisiva: la empresa operadora para Santiago, la Chilian Electric

14 Gall 1995, 17, 19, 62-63; Seidenzahl 1984 [1968], 170-171; Deutsche Ueberseeische Bank 1936; Krebs, Pommerenke 1913, 83-84; Loscertales 2002, 128. Cuando el BAT abrió oficinas en Madrid en 1907, absorbió a la sociedad sucesora del Banco Hispano Alemán, la Guillermo Vogel \& Co. (https://www.db.com/spain/es/content/952.html).

15 Gall 1995, 3, 23, 62-63; Müller 2005, 1; Brasilianische Bank für Deutschland 1912; Geschäftsbericht Norddeutsche Bank in Hamburg 1895, 8; Geschäftsbericht Disconto-Gesellschaft 1887, 5 y 1895, 4 [Los Geschäftsberichte (memorias anuales) son accesibles en internet: www.bankgeschichte.de]; Krebs, Pommerenke 1913, 83-84. 
Tramways \& Light Co. Ltd. (CET\&L), fue formada con capitales alemanes y registrada en Londres en mayo del 1898; la Elektrische Straßenbahn Valparaíso A.-G. (Empresa de Tranvías Eléctricos de Valparaíso, ETEV) fue fundada y registrada en septiembre de 1903 en Berlín. Al comenzar la Primera Guerra Mundial en el año 1914, junto con el ferrocarril de Berlín a Bagdad, la DUEG/ CATE representó la mayor inversión del capital alemán en el extranjero y en su sindicato, en ese momento, ya estaban representados casi todos los principales bancos alemanes. 16
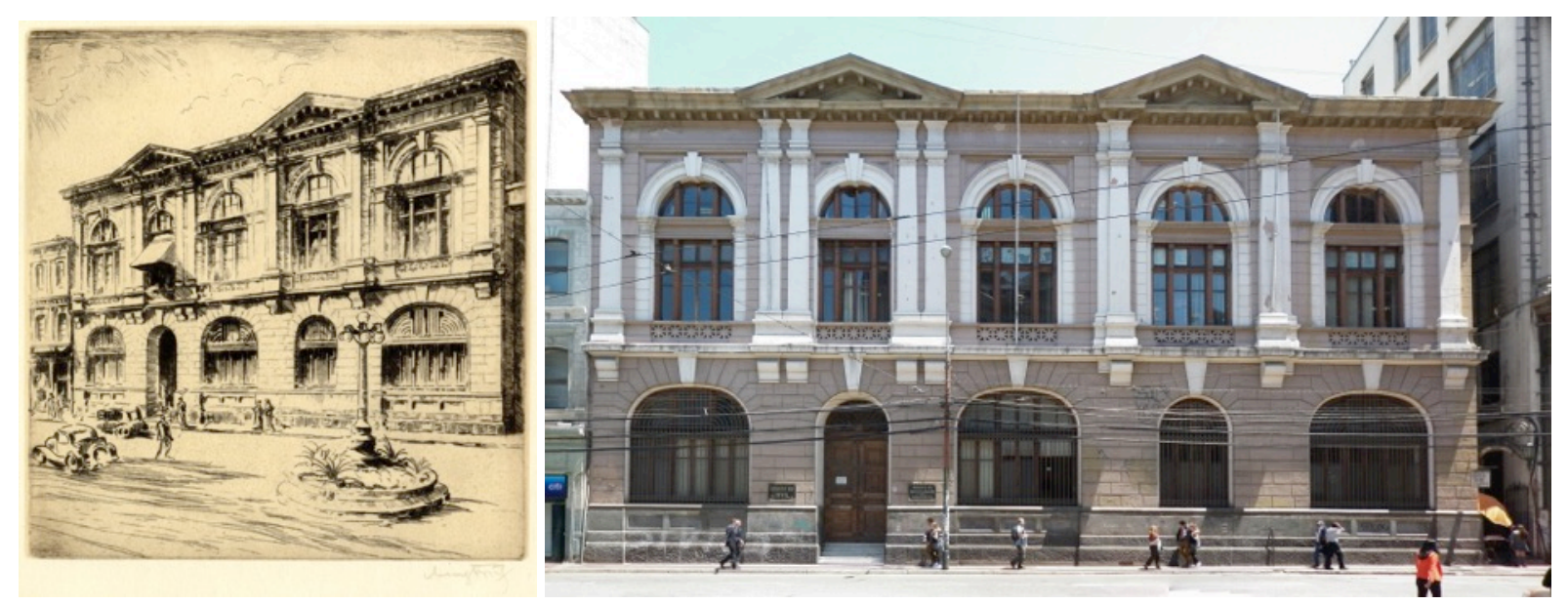

Figura 4: La filial del Banco Alemán Transatlántico en Valparaíso, hoy es reconvertida en Registro Civil. Fuente: Instituto Histórico del Deutsche Bank, Frankfurt am Main; Foto: Marion Steiner, 2015.

El 50 por ciento del capital inicial de la CET\&L en mayo de 1898, y el 10 por ciento del capital para la creación de la DUEG/CATE en enero del mismo año fue otorgado por Julius Wernher (1850-1912) y Alfred Beit (1853-1906), los dos de origen alemán. Se habían convertido en hombres ricos gracias a la minería de diamantes y de oro en Sudáfrica, y en la década de 1880 se instalaron en Londres, el centro financiero más importante del mundo de aquellos tiempos. Desde aquí, invirtieron gran parte de su fortuna en una amplia diversificación de su empresa Wernher, Beit \& Co. y participaron en varias empresas en todo el mundo, y especialmente en toda una serie de proyectos de electrificación de tranvías. El buen contacto que estos dos personajes tenían con los actores líderes de la AEG y del Deutsche Bank y su alta participación de un 50 por ciento en la creación de la CET\&L, sugiere que fueron ellos la razón por la cual esta empresa fue registrada en Londres y no en Berlín.17

El capital suficiente era un requisito imprescindible para poder realizar los proyectos de electrificación debido a que la construcción de las centrales, subestaciones, redes y demás infraestructura como los tranvías eléctricos y sus rieles eran sistemas de gran escala y costosos, necesitando de un pre-financiamiento. Aun suponiendo que la iniciativa para la creación de empresas eléctricas operadoras fuese sobre todo aportado por los fabricantes, como lo describen ya detalladamente varias historiografías de estas empresas al día de hoy, los historiadores de la economía William J. Hausman, Peter Hertner y Mira Wilkins, en su libro publicado en 2008 titulado Global electrification. Multinational Enterprise and International Finance in the History of Light and Power, 1878-2007, plantean que en última instancia fueron los bancos, especialmente a raíz de sus excelentes conexiones internacionales, quienes facilitaron la difusión de la nueva tecnología por el mundo entero.

Entre 1900 y 1904 culminó un proceso mundial de concentración de las empresas constructoras eléctricas, el cual en Alemania fue llamado Elektrokrise. Durante esta crisis fusionaron, entre otras, la compañía berlinesa Union Elektricitäts-Gesellschaft (UEG) con la AEG y la compañía Schuckert \& Co. de Nuremberg con Siemens. Además, con el motivo de asegurar su propia supervivencia y, a la vez, de repartirse el mercado mundial entre ellas, las grandes compañías firmaron acuerdos mutuos. Así por ejemplo, la AEG y Siemens en 1898 firmaron un convenio sobre sus negocios respectivos

16 Hausmann et al. 2008, 99-100; Hertner 2013, 92; CET\&L 1898; Reitmayer 1999, 45, 142, 184-185 (nombra más ejemplos para Personalunionen entre el Deutsche Bank y empresas industriales alemanas); Jacob-Wendler 1982, 152; Couyoumdjian 1986, 221; Seidenzahl 1984 [1968], 170-174.

17 Seidenzahl 1984 [1968], 170; Jacob-Wendler 1984, 167, 324; Trevelyan 2012; Albrecht 2012. 


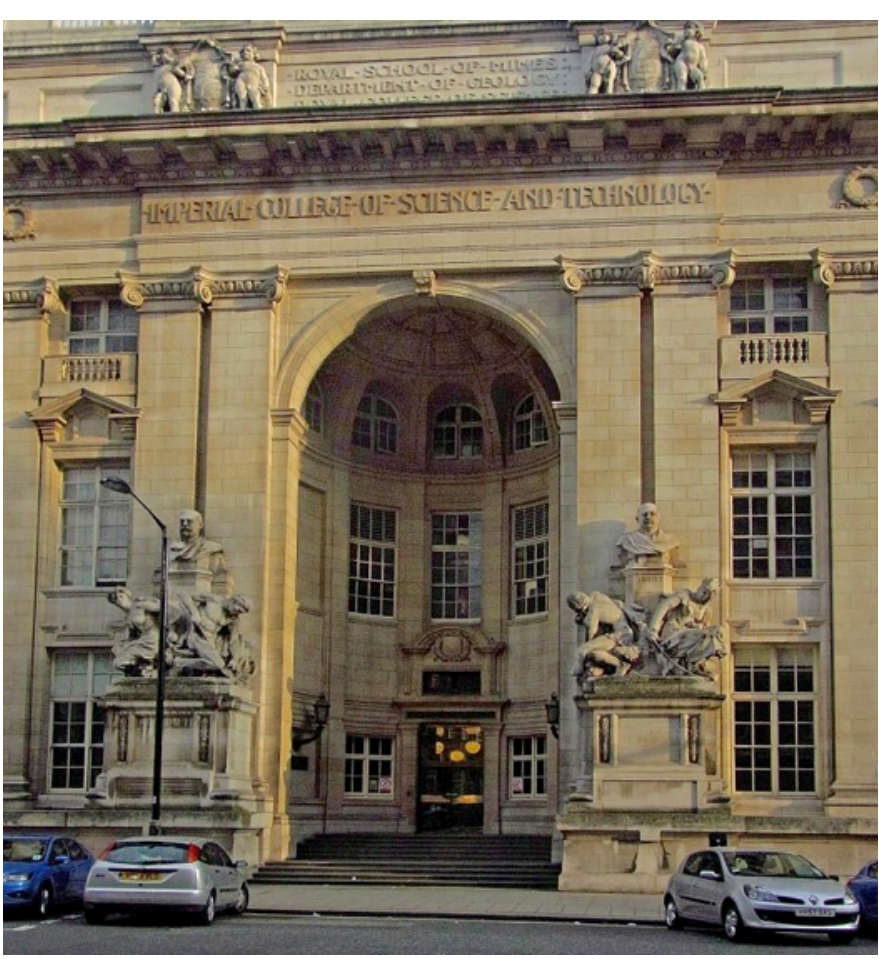

Figura 5: Royal School of Mines del Imperial College London, con las estatuas de Werner Beit y Julius Wernher situadas a ambos lados de la entrada. Foto: Rainer Halama, 4 de agosto de 2014, Wikimedia CC BY-SA 3.0.

en América del Sur, en el cual acordaron, entre otras cosas, que la AEG tuviese "mano libre" en Valparaíso y, a cambio, dejaría a Siemens el rol líder en la ciudad portuaria brasileña de Salvador de Bahía. En 1903, la AEG firmó otro convenio con la empresa fabricante estadounidense General Electric, en el cual ambas compañías establecieron zonas de operación: la General Electric poseería el monopolio de productos y tecnología en Estados Unidos y Canadá; la AEG, a cambio de ello, poseería el monopolio en Europa (con la excepción de Inglaterra, Francia, España e Italia, países para los cuales se negoció establecer acuerdos especiales), Rusia, Turquía y los Balcanes. 18

A parte de asegurarse los mercados de las regiones del mundo más cercanas al propio territorio nacional, llamados Heimatmärkte en alemán, el acuerdo de 1903 definió además "zonas neutrales", a las cuales también pertenecía América del Sur. En esta región, según explica la historiadora chilena Silvia Castillo en su libro sobre la CET\&L, "las dos empresas tendrían la posibilidad de actuar simultáneamente, aunque de modo independiente"19. Aparentemente, como América del Sur era considerado una región muy atractiva económicamente en esos momentos, las compañías no habrían querido correr el riesgo de firmar acuerdos prematuros para sus mercados, pero al mismo tiempo sentaron las bases para una futura cooperación entre ellas con el motivo de hacer frente común a otros eventuales competidores. Así, dentro de muy poco tiempo, se formó de hecho una constelación cruzada entre las cuatro grandes compañías fabricantes alemanas y estadounidenses que dominaron el mercado eléctrico mundial: la AEG cultivó relaciones más estrechas con la General Electric, mientras que Siemens a menudo se asoció con Westinghouse. Esta situación igualó a una concentración máxima de los monopolios de las grandes empresas eléctricas a nivel mundial.

\section{Chile y el "fantasma de la fuerza motriz"}

En las dos ciudades más importantes de Chile, la capital Santiago y la ciudad portuaria cosmopolita de Valparaíso, la cual a raíz del rol importante que tenía su puerto en el comercio mundial de aquella época era también el centro comercial y financiero del país; en ambos, la AEG ya había intentado entrar en el negocio eléctrico años antes de que empezara la crisis eléctrica mundial. A partir de principios de los años 1890, varios agentes e intermediarios de la empresa alemana actuaban en Chile para convencer a las municipalidades que contratasen a la AEG para electrificar su alumbrado público y los tranvías ${ }^{20}$. Siguiendo con su modelo español exitoso, la estrategia de la AEG consistía en crear empresas operadoras para ambas ciudades, las cuales a continuación debían contratar, según la lógica del Unternehmergeschäft, a la misma AEG para que construyera las instalaciones, obras con cuya ejecución la empresa fabricante contaba con obtener sus ganancias. Fue en 1897 para Santiago y en 1902 para Valparaíso que los intermediarios de la AEG en Chile, después de algunas complicaciones interesantes en ambos casos, habrían logrado finalmente firmar contratos con ambos municipios. Ya durante la preparación de las bases de licitación para estos contratos hubo intensos debates entre los concejales sobre el uso de la fuerza motriz del

\footnotetext{
18 Pohl 1988, 161, 167, 260-261; Nazer et al. 2005, 20; Castillo 1994, 15; Wilkins 1970, 93-96.

19 Castillo 1994, 15.

20 Véase por ejemplo el acuerdo entre AEG y Siemens de 1898 ya mencionado y Jacob-Wendler 1982, 170, 327.
}

(C) Labor \& Engenho, Campinas [SP] Brasil, v.11, n.4, p.446-476, out./dez. 2017. 
agua, y a la hora de redactar las versiones finales de los contratos, el uso de la fuerza hidráulica fue especificado claramente como precondición en los documentos respectivos 21.

Cuando se iniciaron, primero en Santiago a finales de 1898, los preparativos para la construcción del sistema eléctrico, muy pronto surgieron los primeros debates entre la empresa y la municipalidad respecto al uso de la fuerza motriz del agua, quedando en evidencia que los intereses y motivaciones de cada uno de los varios grupos de actores involucrados eran esencialmente diferentes:

Un interés clave de la Bau-Kommission (comité de construcción) de la AEG, que estaba a cargo de realizar in situ la construcción de las instalaciones para la empresa operadora CET\&L, era implementar las técnicas estándares existentes que la empresa ya utilizaba en otras muchas partes del mundo. En general, eran los sistemas térmicos que habían comprobado ser eficaces en Alemania y España, que buscaban también instalar en las demás ciudades donde habían sido contratados sus servicios, y ciertamente no era del interés de la empresa fabricante invertir en el largo y costoso proceso de encontrar nuevas soluciones técnicas adaptadas e idóneas a las condiciones geográficas y necesidades específicas de los actores locales. Hubiese significado un esfuerzo extra para la AEG y una menor ganancia, y por tanto, un esfuerzo tal se realizó sólo cuando fue absolutamente necesario. El interés de los fabricantes consistía en ganar lo máximo posible de clientes nuevos con el mismo producto de siempre, evitando inversiones adicionales. El espléndido catálogo de 400 páginas sobre "Tranvías eléctricos" que la AEG publicó por cuenta propia en 1900 en tres idiomas (alemán, inglés y francés), ricamente ilustrado con fotografías y planos y demostrando las variadas posibilidades de aplicación de esta nueva tecnología, es un muy buen ejemplo de cómo las empresas constructoras promovieron sus productos y sistemas ya establecidos frente a los potenciales clientes $^{22}$. El principal interés de las empresas constructoras era la venta de este tipo de "soluciones de catálogo", según una lógica del menor gasto posible.

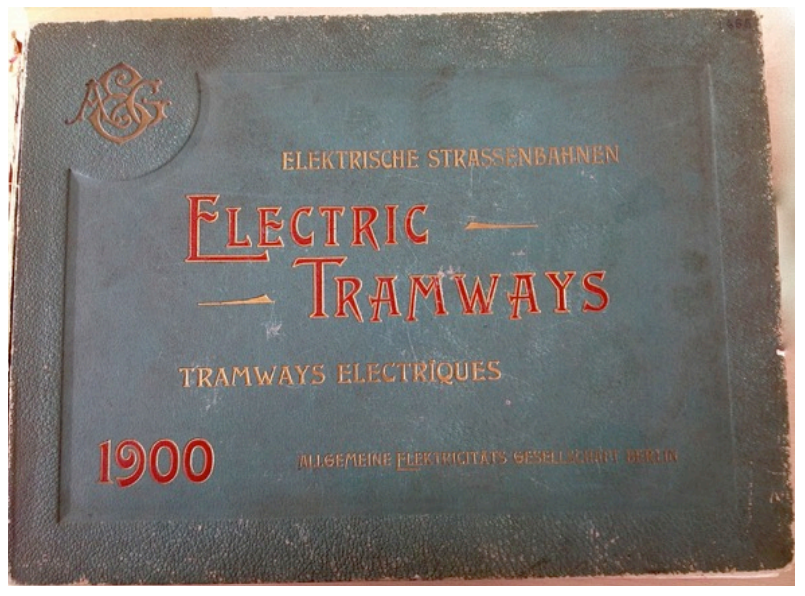

Figura 6: Catálogo trilingüe sobre tranvías eléctricos, editado por la AEG en 1900. Fuente: Museo Alemán de la Tecnología en Berlín, Archivo AEG.

Los intereses y motivos de los concejales de la Municipalidad de Santiago, del lado opuesto, eran muy diferentes. Para ellos, la electrificación del alumbrado público y del tranvía de su ciudad representaba un importante proyecto de modernización urbana que debía mejorar su calidad de vida. Tradicionalmente, la mayoría de la élite social y política del país era "también dueños de gran parte de la tierra", y "la propiedad agraria era requisito indispensable para el éxito social" en Chile en esa época, como señaló el historiador chileno Ricardo Couyoumdjian. Pero a finales del siglo XIX, las atracciones de la vida urbana llevaron a la élite del país "a instalar casas en Santiago" y volvieron "a sus fundos y haciendas solamente a pasar las vacaciones" 23 . Aspiraban a un estilo de vida urbano moderno según el modelo europeo. Desde siempre la élite de la sociedad chilena, cuya representación también dominó las Municipalidades, estaba muy al tanto de todo tipo de innovaciones que se realizaban en Europa. Como por ejemplo de lo que ocurría en Suiza y Noruega, países similares y posibles de comparar con Chile en cuanto a su abundancia de montañas y ríos, a pesar de sus diferencias climáticas. En ellos ya se utilizaban con éxito la fuerza motriz del agua que representaba para ellos una fuente de energía natural y barata. A raíz de esto, en Chile también los concejales empezaron a soñar con la aplicación de las tecnologías correspondientes. Existía además, ya en este momento, un ejemplo muy exitoso de la utilización de la fuerza hidráulica en su propio país.

\footnotetext{
21 Municipalidad de Valparaíso 1902, 995-1010; Flores 2000, 100-102; CET\&L 1914, 44-47, 117-130.

22 Allgemeine Elektricitäts-Gesellschaft 1900.

${ }^{23}$ Couyoumdjian 1986, 2-8.
} 
En 1896, unos 500 kilómetros al sur de la capital, la Compañía de Lota había puesto en servicio Chivilingo, la primera central hidroeléctrica de Chile y la segunda en América del Sur, que dotaba de electricidad a las minas de carbón de Lota y a su ferrocarril subterráneo como también al alumbrado público y al tranvía de la ciudad, inaugurado en el mismo año. La central fue diseñada por la compañía de Thomas A. Edison y equipada con generadores de la compañía Schuckert \& Co. de Nuremberg, la cual construyó también las cuatro locomotoras para el tranvía eléctrico. La construcción de Chivilingo se debe a la iniciativa de doña Isidora Goyenechea de Cousiño (1836-1897), de nacionalidad chilena, dueña de las minas de Lota y considerada en aquellos momentos la mujer más rica del mundo. Pasó mucho de su tiempo en Europa, y de su enorme influencia social es testimonio hasta el día de hoy una calle en el elegante distrito XVI de París, la cual en su honor fue nombrada Rue de Lota. La Compañía de Lota fue uno de los primeros clientes de electricidad en Chile, y su motivo primordial para aplicar la nueva tecnología fue el de mejorar la eficiencia de la mina24.

En este contexto de intereses divergentes de los actores involucrados, los contratos que habían firmado sus intermediarios y que comprometían a la AEG a construir sistemas hidroeléctricos en Santiago y Valparaíso, representaban entonces en cierta medida un problema para la empresa fabricante alemana. Múltiples fuentes demuestran de hecho que Emil Rathenau en esos momentos no era muy convencido de que la energía hidroeléctrica fuese una buena opción para su negocio. Rathenau incluso parece haber tenido una aversión fundamental en contra de esta posible fuente energética y repetidamente habló del "fantasma de la fuerza motriz del agua" (Gespenst der Wasserkräfte). Esa aversión se expresaba particularmente bien en el caso de España a principios del siglo XX, y es posible que en sus declaraciones correspondientes hayan jugado un rol determinante las experiencias negativas obtenidas por su empresa previamente en Chile, a las cuales me referiré más abajo. En abril de 1902, Emil Rathenau escribió al Presidente de la Sevillana:

El fantasma de la fuerza motriz del agua no sólo recorre España; ha completado su recorrido por el mundo, y de los que han invertido su capital en las instalaciones costosas creyendo en su rentabilidad y ganancias, casi todos han realizado que incluso los países donde el carbón es más caro aún que en Sevilla, no pueden permitirse el lujo de tales instalaciones para el efecto del alumbrado. Ha especificado Ud. con precisión las razones: el costo del combustible más caro es inferior a los intereses y comisiones que causa la instalación más económica ${ }^{25}$.

Los sistemas hidráulicos y eléctricos, continuó, podrían "como máximo ser usados para fines electro-químicos". Pero incluso en los casos en que los costes de construcción fuesen relativamente bajos y la captura y el transporte de la electricidad también necesitasen poco gasto, la AEG hasta entonces "no se ha decidido de servirse del recurso natural barato en lugar del vapor porque muchos cálculos repetidos resultaron a favor de este último." 26

Un año más tarde, el 4 de diciembre de 1903, Emil Rathenau expresó una vez más y con toda claridad su escepticismo sobre el riesgo que representaba, en su opinión, el uso de la fuerza hidráulica. En su función de director de la CET\&L de aquel momento, Rathenau recibiría una carta de parte de Samuel Kocherthaler de la Gesfürel, un holding27 que ya había participado en 1898 con un 25 por ciento en la fundación de la CET\&L para financiar los negocios en Santiago de Chile, que decía:

Por encomienda de la Disconto-Gesellschaft, me vino a ver un intermediador de Frankfurt, el Sr. Cesar Strauss [...]. Me ofreció fuerzas de agua en el Pirineo que dice que proporcionarían 18.000 HP y distan alrededor de $180 \mathrm{~km}$ de Barcelona y de la gran región industrial catalana que es conocida por ser receptiva a esta y aún mayores cantidades de energía 28.

\footnotetext{
24 Morrison 2013, 127; Robinson Wright 1904, 318; http://web.archive.org/web/20140810184733/http:/ www.palaciocousino.co.cl/isidora.html [accedido 25.4.2017].

25 Transcripción de partes de esta carta en Loscertales 2002, 333; original en el Archivo histórico del Deutsche Bank en Frankfurt am Main, síg. S 1213, Sevillana Electricitäts-Gesellschaft.

26 Ibid., p. 333.

27 La Gesellschaft für Elektrische Unternehmungen (Gesfürel), fundada en 1894, era el holding de la empresa constructora berlinesa Union Elektricitäts-Gesellschaft (UEG) la cual fusionó en 1904/05 con la AEG (Jacob-Wendler 1986, 167, 324).

${ }^{28}$ SDTB, Archivo AEG, Berlín, síg. I.2.060 A-FA 01065, 109 (Kocherthaler a Rathenau, 4.12.1903).
} 
Su propia empresa, dijo Kocherthaler, no tenía "mayor interés" en esta oferta (probablemente era un negocio demasiado concreto para un holding), pero en el caso de que Rathenau tuviera "una opinión diferente" y quisiera recibir al Sr. Strauss "entre hoy y mañana", le ofreció establecer el contacto. Dado que la AEG ya operaba el sistema térmico de la Barcelonesa en este tiempo, debe haberse sentido interesada en expandir sus negocios en Cataluña. No obstante, Emil Rathenau respondió a Kocherthaler el mismo día,

que la fuerza motriz del agua es un negocio riesgoso. Nosotros sólo nos lanzamos en ello cuando estamos obligados a hacerlo, y creo que en el caso de Barcelona, deberíamos contentarnos por el momento con nuestras instalaciones existentes ${ }^{29}$.

Hay varias razones por las cuales nos podría sorprender hoy en día la aversión que tenía Emil Rathenau en su momento en contra de la fuerza motriz del agua: Una es, seguramente, la conciencia que tenemos hoy, en un contexto de cambio climático, sobre el uso del agua como una posible fuente energética más natural, más sostenible e incluso más barata a largo plazo. Pero el escepticismo de Rathenau también nos puede sorprender con respecto al desarrollo tecnológico de la época, porque era precisamente la AEG quien en la Exposición Internacional de Electricidad en Frankfurt en 1891 habría triunfado con un gigantesco experimento de transmisión de energía hidroeléctrica. En un proyecto que se convirtió en la atracción principal de la exposición, la cual registró más de un millón de visitantes entre mayo y octubre de 1891, logró generar electricidad en una central hidroeléctrica en Lauffen a 175 kilómetros de distancia y transmitir la corriente hasta el recinto ferial en Frankfurt donde, entre otras cosas, alumbraba cientos de bombillas e iluminaba una cascada artificial multicolor de unos 7 metros de altura ${ }^{30}$.

Hay que señalar, sin embargo, que los inventos tecnológicos necesarios para el éxito de este proyecto, en cuanto a la parte hidroeléctrica no fueron realizados por la AEG berlinesa, sino más bien por la Maschinenfabrik Oerlikon (MFO), una empresa fabricante suiza con sede cerca de Zúrich. Según presume en su tesis de habilitación el historiador suizo David Gugerli, la AEG desde el principio había considerado el proyecto "demasiado grande para una sola empresa, tanto en términos de capacidades técnicas como organizativas", y como no había encontrado socios adecuados en Alemania, finalmente decidió unir fuerzas con la MFO suiza. Los dos ingenieros jefes responsables de la parte hidráulica del proyecto eran el suizo Charles Brown (1863-1924), director del departamento eléctrico de la MFO desde 1885, y el alemán Walter Boveri (1865-1924) quien el mismo año 1885, después de graduarse de la Escuela Real de Ingeniería Mecánica de Nuremberg, entró a trabajar en la MFO y en 1892 adaptó la nacionalidad suiza31.

La exposición de Frankfurt de 1891 coincidió, además, con la ardiente disputa sobre qué corriente poseía un sistema tecnológico superior: la corriente directa, preferida por ejemplo por la empre-a Siemens \& Halske, o la corriente alterna, preferida por la AEG. Desde la perspectiva de la AEG, la exposición sirvió entonces ante todo para demostrar que la tecnología del futuro era la utilizada por ellos, lo cual logró promover con el mayor éxito posible. La cascada iluminada de colores en Frankfurt se convirtió en el símbolo del triunfo de la AEG: la construcción social que acompañaba la exposición, la convirtió en "un nuevo punto de referencia, como un posible futuro paradigma", como señaló David Gugerli, y el consecuente "efecto catalítico de la exposición de Frankfurt" aumentó considerablemente el prestigio de los productos de la AEG. No menos importante, esta nueva atención permitió además a las empresas fabricantes aumentar el interés de los grandes bancos como inversores en sus proyectos de electrificación, donde previamente eran sobre todo las municipalidades y empresas privadas quienes proporcionaban el capital 32 .

Pero a Emil Rathenau, simplemente, no le gustaba la hidroelectricidad. Sevilla, donde la AEG participaba en el negocio eléctrico desde 1894, es otro ejemplo impresionante. En 1904, un grupo de industriales españoles alrededor de los hermanos Benjumea fundó aquí la Compañía Hidroeléctrica

\footnotetext{
${ }^{29}$ SDTB, Archivo AEG, Berlín, síg. I.2.060 A-FA 01065, 112 (Rathenau a Kocherthaler, 4.12.1903).

30 Muy buena descripción del proyecto realizado por AEG-MFO en Gugerli 1996, 104-117.

31 Gugerli 1996, 106.

32 Gugerli 1996, 94-96, 104, 108, 115.
} 
del Guadiaro la cual apuntaba a firmar un contrato de suministro con la Sevillana. Si bien la AEG era la propietaria de la Sevillana, no podía rechazar de plano esta propuesta, ya que en el Consejo de administración de la Sevillana se encontraba el abogado de la concesionaria de aquella hidroeléctrica. Esta nueva compañía tenía previsto comprar el material para su central con Siemens \& Halske y contratar a la empresa madrileña Levi y Kocherthaler para que realizara las instalaciones. Resulta que Levi y Kocherthaler no eran sólo representantes de AEG, sino también una empresa instaladora y como tal, siempre interesados en un negocio. Emil Rathenau se empeñó entonces en impedir, por cualquier medio, la construcción de la nueva central hidroeléctrica en Sevilla. En diciembre de 1904 viajó a Madrid para convencer a Julio Kocherthaler de no seguir con el proyecto. A Arthur Gwinner del Deutsche Bank le instruyó a hacer lo mismo en Berlín con Siemens \& Halske. La central fue construida a pesar de estos esfuerzos y el material vino al final de la MFO suiza. Otra de las muchas medidas activas que tomó Emil Rathenau para protegerse de "la inminente inundación por las hidroeléctricas" era, como puso de manifiesto Javier Loscertales en su tesis doctoral, la compra a través de su propia empresa de distintas concesiones de agua, las cuales por supuesto, no tenía intención de utilizar33.

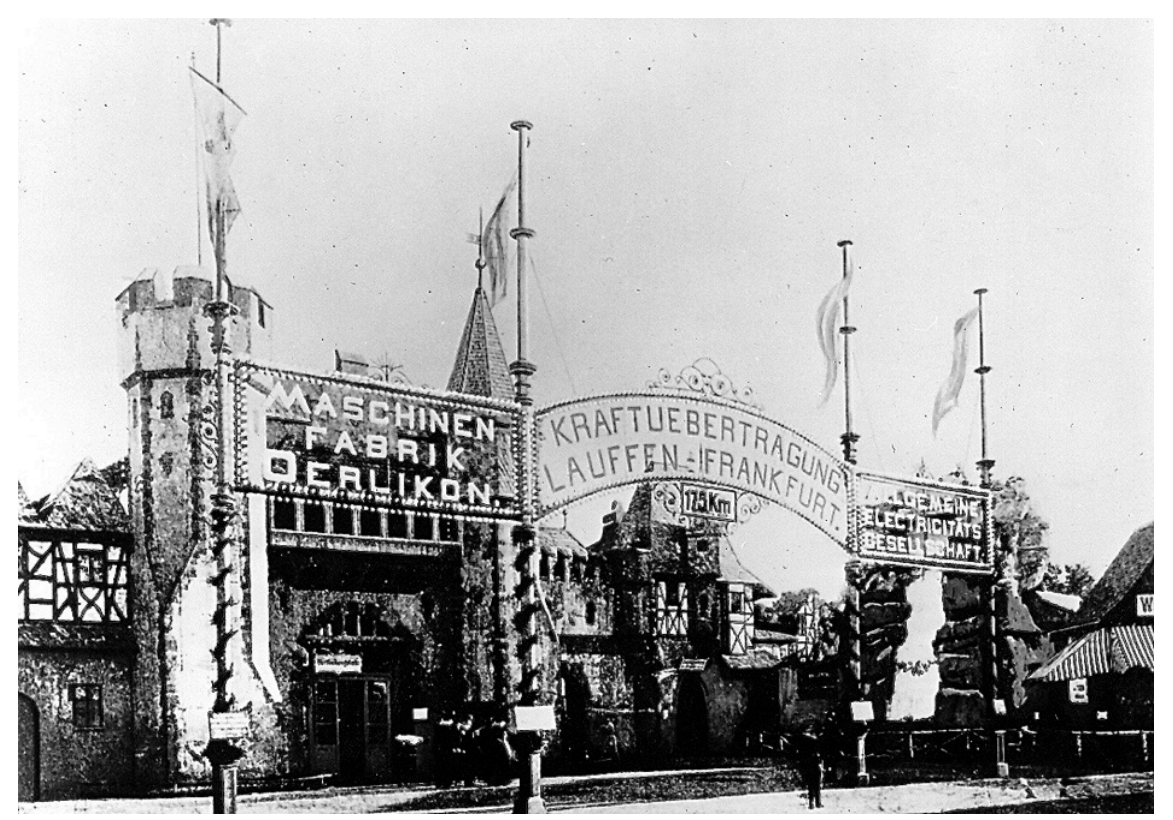

Figura 7: Entrada a la Exposición Internacional Electrotécnica de Frankfurt am Main, 25 de agosto de 1891. El arco de las arcadas era equipado con 1000 bombillas de luz, la corriente eléctrica se transmitía a través de una línea de transmisión de 175 $\mathrm{km}$ desde Lauffen am Neckar al recinto ferial. Al fondo, se puede ver la cascada de agua artificial. Fuente: de.wikipedia.org Internationale Elektrizitätsausstellung; foto tomada: 12.9.1891; scan: 2.3.2007; fotógrafo desconocido; dominio público.

\section{Las disputas entre empresa y municipalidad en Santiago}

En Santiago, las disputas sobre el uso de la fuerza motriz del agua entre la empresa y los actores locales empezaron ya con la sesión constitutiva del Comité local de la CET\&L, la cual se celebró el 4 de agosto de 1898. Es posible reconstruirlas a base de las actas de las sesiones de la Municipalidad de Santiago y de las transcripciones de las actas de las sesiones del Comité local de la CET\&L que se han conservadas de todo este periodo hasta e incluyendo el año 1902.34

\footnotetext{
33 Loscertales 2002, 174-175, 189.

${ }^{34}$ Actas de las sesiones de la Municipalidad de Santiago publicadas en Municipalidad de Santiago 1890-1911, 25 tomos, incluyen todas las actas de las sesiones municipales 1892-1910; citados en adelante como ACTAS MUNI SANTIAGO, [sesión], [fecha de la sesión], [tomo]: [página]. /// Actas de las sesiones del Comité local de la CET\&L: estaban en el archivo del Centro de Documentación de la empresa Chilectra cuando aún existía en los años 1990; hoy en día parece que han desaparecido o por lo menos la empresa no permite el acceso público. No obstante, se han conservado las transcripciones de las actas hechas por Silvia Castillo y su equipo cuando investigaba para su libro de 1994. Agradezco a Silvia su amable apoyo y solidaridad de investigadora mujer que me permitió consultar estas transcripciones y demás documentos que forman parte de su Archivo personal sobre la historia de la CET\&L y de Chilectra y que hoy en día se puede consultar en el Instituto de Historia de la Pontificia Universidad Católica de Chile en Santiago; citados en adelante como ACTAS CL CET\&L, [sesión], [fecha de la sesión]: [página en el cuaderno de las transcripciones].
} 
Por parte de la empresa, el análisis de la composición del Comité local de la CET\&L permite identificar los actores individuales en Santiago y sus roles respectivos. Durante los primeros años, el comité fue presidido por el respectivo director del BAT Valparaíso, siendo entonces el primer presidente del Comité local de la CET\&L en Santiago Paul Millington-Herrmann (1858-1935) del Deutsche Bank, quien anteriormente, al igual que Arthur Gwinner, había vivido en España donde en algún momento entre 1881 y 1883 se habían conocido personalmente. En octubre de 1895, MillingtonHerrmann fue mandado a Chile para servir de director adjunto del recién fundado BAT en Valparaíso, y en diciembre de 1896 ascendió al cargo de director de aquella filial, la cual era en ese entonces la principal representación del banco en Chile. Regresó a Alemania en 1899, y durante la década de 1900 creó la red de filiales del Deutsche Bank en Sajonia. A partir de 1911, ascendió a posiciones de alta responsabilidad en la sede del Deutsche Bank en Berlín35.

Hubo representación también en el Comité local de la CET\&L del Banco de Chile y Alemania, una sociedad filial del único otro banco de acciones alemán importante que, aparte del Deutsche Bank, ya operaba en Chile en ese momento. Una función de asesor al comité tenía el ingeniero y empresario chileno Santiago A. Ossa (fechas de nacimiento y fallecimiento desconocidas), el iniciador del proyecto de electrificación de Santiago, quien ya en enero de 1893 había presentado la primera propuesta para dotar a la ciudad "de un servicio de tranvías y alumbrado público eléctrico, a partir de una central generadora de electricidad que se construiría utilizando la concesión que había obtenido de las aguas del río Maipo". Fue precisamente la posesión de esta concesión de agua la que le aseguró a Ossa su integración en la CET\&L. Los contratos correspondientes con Emil Rathenau fueron firmados en septiembre de 1897 en Berlín por el ingeniero y empresario Pedro Merry del Val y Zulueta (fechas de nacimiento y fallecimiento desconocidas), descendiente de una antigua familia aristocrática español-irlandesa, quien se había criado en Londres como hijo del cónsul español. En el caso de la electrificación de Santiago, sirvió como mediador entre los dos mundos y también fue miembro del Comité local de la CET\&L en Santiago, hasta mediados de 190036.

Desde su primera sesión en agosto de 1898, en el Comité local de la CET\&L estuvo representado además, con Friedrich Mertsching, un empleado de la Bau-Kommission de la AEG; otro, Hugo Zimmermann, integró el comité en noviembre. Durante los próximos años, como ingenieros jefes de la empresa constructora AEG, ellos dos tuvieron a cargo la instalación del sistema de alumbrado y la red de tranvías eléctricos en Santiago. Hugo Zimmermann había dirigido previamente la construcción de los sistemas de alumbrado de la AEG en Madrid, Barcelona y Sevilla, por lo cual se manejaba perfectamente con el idioma. En Santiago, dirigió la Sección del alumbrado y de la energía, y a partir de septiembre de 1899 proyectó además el Departamento comercial. Friedrich Mertsching por su parte estuvo a cargo de la Sección de tracción eléctrica y dirigió la instalación de la vía37.

En estas constelaciones de actores se inició la construcción del sistema térmico, el cual estaba previsto como una solución temporal y solo debía seguir funcionando como reserva una vez puesto en servicio el sistema hidroeléctrico. Apenas arrancadas las obras, los concejales de la Municipalidad de Santiago empezaron a sentir recelo de que la empresa, una vez que se hayan producido hechos consumados con la construcción del sistema termoeléctrico acabado, cumpliría realmente su promesa de construir el sistema hidroeléctrico. Con muy buena razón temían que la empresa constructora quería evitar en la medida de lo posible la búsqueda de soluciones técnicas nuevas para las situaciones específicas que presentaba el territorio. Los estudios sobre la rentabilidad y viabilidad del proyecto hidroeléctrico en Santiago, existentes hasta ese momento, no fueron muy bien elaborados según la opinión de los dos ingenieros que formaban parte de la Municipalidad de Santiago, los concejales Meyerholz y Larenas. En un informe correspondiente constataron que Pedro Merry del Val solo había presentado ante-proyectos hasta esa fecha y las consideraron ser poco significativos ${ }^{38}$.

35 CET\&L 1898, 13; "Dr. h.c. Paul Millington-Herrmann. Zu seinem siebzigsten Geburtstag”. Hamburger Fremdenblatt. 9.11.1928; Deutsche Ueberseeische Bank 1936, 23-24, 67, 72, y otras.

36 Nazer et al. 2005, 26; Castillo 1994; Anales del Instituto de Ingenieros de Chile 1893. Año IV, Tomo V, 417-425 y 563-571; CET\&L 1899, 398; ACTAS CL CET\&L, 57a sesión, 23.5.1900, 120.

37 Dávila 1901, 77-78; CET\&L 1898, 14-15; Castillo 1994, 23, 25, 29.

${ }^{38}$ ACTAS MUNI SANTIAGO, informe Meyerholz y Larenas, 2.10.1899, Tomo XI.2, 277-282. 


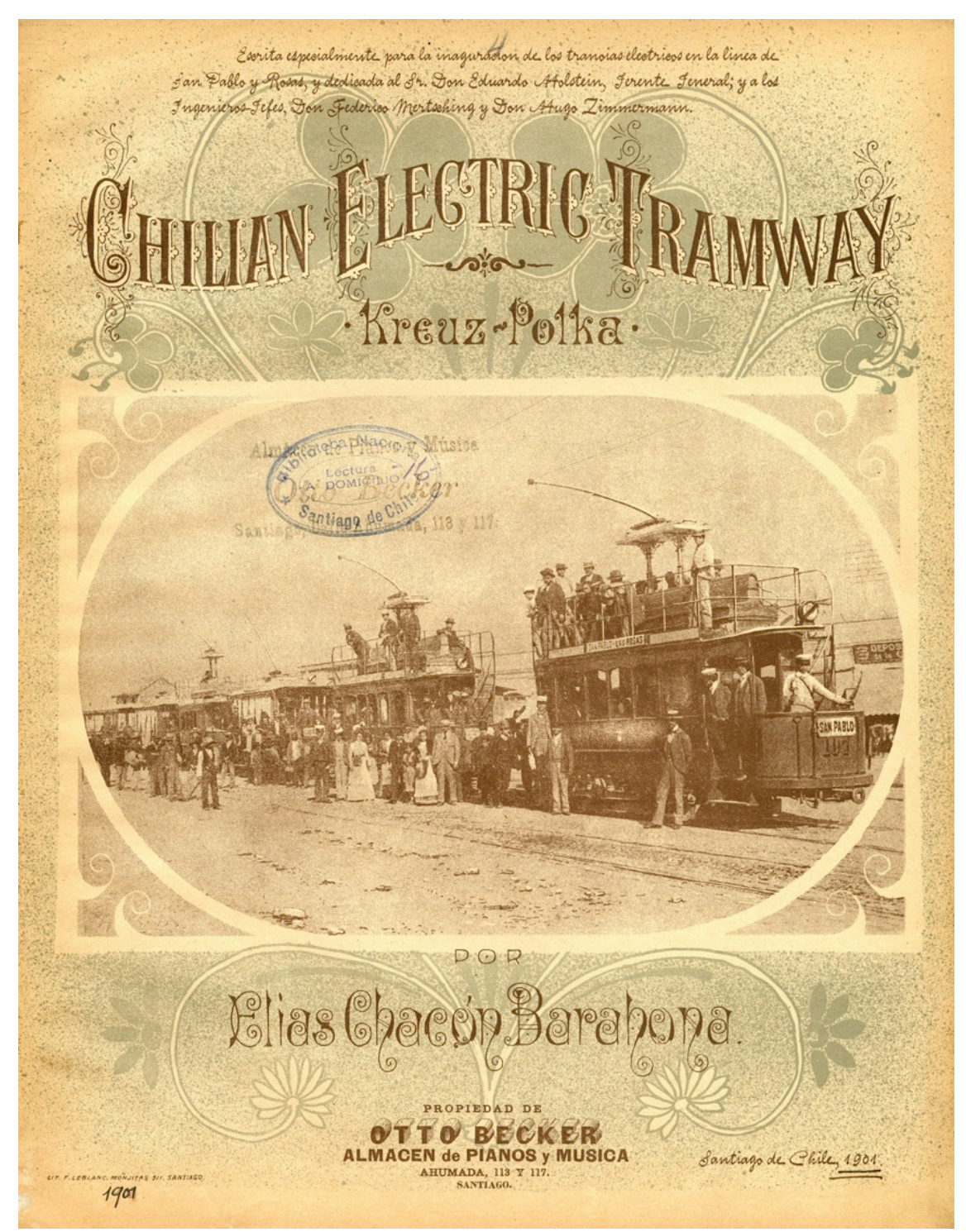

Figura 8: Portada de una polka "Escrita especialmente para la inauguración de los tranvías eléctricos en la línea de San Pablo y Rosas, y dedicada al Sr. Don Eduardo Holstein, Jerente Jeneral [de la CET\&L]; y a los Ingenieros Jefes, Don Federico Mertsching y Don Hugo Zimmermann." Santiago de Chile, 1901 Fuente: Biblioteca Nacional de Chile, Archivo de Música.

Las actas de las sesiones de la Municipalidad de Santiago dan cuenta de estas preocupaciones de los concejales. En su sesión del 17 de octubre de 1898 y "por asentimiento tácito", la Municipalidad acordó "que el señor Alcalde pregunte [a la empresa] cuándo darán cumplimiento al contrato en la parte que establece que deben iniciar trabajos en el rio Maipo para la realizacion del proyecto de traccion i alumbrado eléctrico de Santiago."39 Y en la última sesión del año, el 30 de diciembre de 1898, después de haber señalado que "está la Empresa de Traccion i Alumbrado Eléctricos de Santiago en la obligación de hacer el servicio tomando como oríjen de la fuerza motriz las caidas de agua que pueden producirse artificialmente en el rio Maipo," 40 se tomó, igualmente por unanimidad, el siguiente acuerdo municipal:

1..$^{\circ}$ Exigir de la compañía la iniciación inmediata de los trabajos [...] en el río Maipo para dar cumplimiento al contrato; $2{ }^{\circ}$ En caso negativo o contestación evasiva de la compañía, pedir la disolución del contrato ${ }^{41}$.

Los miembros del Comité local de la CET\&L en su sesión del 5 de enero de 1899, leían la versión oficial de este acta municipal, la cual fue publicada en el periódico El Ferrocarril, quedando así

\footnotetext{
${ }^{39}$ ACTAS MUNI SANTIAGO, sesión 110a ordinaria, 17.10.1898, Tomo X, 399-400. Para darle más autenticidad y permitir que se genere una impresión sobre cómo se hacían, decían y escribían las cosas hace 100 años atrás, la ortografía de todas las citas que siguen concorde con la de los documentos originales.
}

${ }^{40}$ ACTAS MUNI SANTIAGO, sesión 125aㅡ ordinaria, 30.12.1898, Tomo X, 505.

41 ACTAS CL CET\&L, 14aㅡ sesión, 7.3.1899, 43. 
todos alertados ${ }^{42}$. En la sesión del 19 de enero, Edmund J'Anson, el representante del Banco de Chile y Alemania, expresó "que era grave la situación para la compañía, consultando el abogado si podría ser forzada la compañía para usar el agua" 43 . Dos semanas después, en la sesión del 3 de febrero, el mismo J'Anson "expresó la opinión de que el contrato hecho con la Municipalidad [...] implica la necesidad de usar esas aguas (ver art. 32). Por lo que significa, solicita [que] se pidieran instrucciones a Londres"44. En la sesión del 7 de marzo, en el Comité local otra vez se leyó el acuerdo municipal del 30 de diciembre de 1898, nuevamente se estimó "grave el caso" y se acordó que el abogado estudiase el tema ${ }^{45}$.

Luego de eso, sin embargo, al parecer el asunto se detuvo un poco, lo cual no resulta extraño dado que a finales de marzo de 1899 volvió a Alemania Paul Millington-Herrmann, quien sin lugar a dudas había sido el personaje que le daba mayor forma y estructura a las acciones de la empresa operadora in situ desde su creación hasta aquel momento. Su despedida se festejó al término de la sesión del Comité local de la CET\&L el día 7 de marzo de 1899. Y como si la pérdida de este personaje fuese poco, en mayo de 1899, severos problemas surgieron con la construcción de las instalaciones del alumbrado eléctrico en la Alameda de las Delicias, la avenida principal de Santiago, donde al tender los cables de manera subterránea como lo mandaba el contrato, los obreros trabajando para la Bau-Kommission de la AEG destrozaron gran parte de las nuevas aceras recién hechas por otra compañía contratada por la Municipalidad, las cuales en vez de ser bien reparadas, fueron parchadas con asfalto. Esto, por supuesto, no les gustó nada a los concejales quienes, como se ha dicho antes, aspiraban a una ciudad moderna que pudiera incluso pasar a ser el "París de América del Sur". Consideraron tan grave el asunto que llamaron a la policía para que interviniese. Como consecuencia, la construcción del sistema de alumbrado eléctrico quedó parado durante varias semanas ${ }^{46}$.

El 3 de agosto de 1899 finalmente se produjo una reestructuración del Comité local de la CET\&L la cual fue implementada in situ por un representante de la empresa matriz de Londres, Charles Stanhope quien por este preciso motivo emprendió un viaje a Chile. Como parte de esa reestructuración, de un lado fueron expulsados del Comité local los dos representantes de la Bau-Kommission de la AEG quienes a partir de ese momento supervisaron las obras desde el exterior. Es muy probable que el motivo último para tomar esta decisión hayan sido justamente los conflictos de intereses entre la empresa operadora CET\&L y la empresa constructora AEG, los cuales se habían hecho evidentes al momento de ejecutar las obras. Al mismo tiempo, Santiago A. Ossa, quien hasta ese momento solo tenía un papel de asesor en el Comité local, pasó a ser miembro pleno del directorio, confiándole la tarea de representar a la compañía ante la Municipalidad. Como nuevo presidente del Comité local entró Eulojio Altamirano quien, ya a finales de 1896, había sido involucrado en el negocio eléctrico en Santiago en la calidad de abogado de Pedro Merry del Val, y en 1899 ya tenía la reputación de ser uno de los primeros políticos de Chile. Según la dirección de la CET\&L en Europa, tanto Altamirano como Ossa se encontraban "más en contacto con la gente", y las habilidades diplomáticas y culturales, que ambos demostraron frente a los concejales y demás actores locales, parecen haber sido la motivación principal de la CET\&L para confiarles la dirección de su Comité local47.

Pasaron algunos meses en los cuales la compañía se encontraba preparando la puesta en servicio del alumbrado público eléctrico. En Septiembre de 1899 ésta pide a la Alcaldía que designara el barrio o barrios en los cuales se llevaría a cabo primero la iluminación con electricidad. De acuerdo con su postura anterior, la Municipalidad se negó a esto y el 6 de noviembre acordó contestar "que no ofreciéndose a la Corporación luz eléctrica del conforme al contrato [...] generada por fuerza hidráulica, no ha llegado el caso de designar qué luces convendría a la Municipalidad

\footnotetext{
42 ACTAS CL CET\&L, 11aㅡ sesión, 5.1.1899, 37.

43 ACTAS CL CET\&L, 12ª sesión, 19.1.1899, 39.

${ }^{44}$ ACTAS CL CET\&L, 13a sesión, 3.2.1899, 41. Contrato en CET\&L 1914, 117-130 (art. 32: véase p. 126).

45 ACTAS CL CET\&L, 14aㅡ sesión, 7.3.1899, 43-44.

46 ACTAS CL CET\&L, 14aㅡ sesión, 7.3.1899, 42; ACTAS CL CET\&L, 17aㅗ sesión, 24.5.1899, 49; ACTAS MUNI SANTIAGO, sesión 141aㅡ ordinaria, 15.5.1899, Tomo XI.1, 687-691; sesión 144ํa ordinaria, 5.6.1899, Tomo XI.1, 767-769 y sesión 147ạ ordinaria, 30.6.1899, Tomo XI.1, 782.

${ }^{47}$ ACTAS CL CET\&L, 20ª sesión, 3.8.1899, 53; CET\&L 1914, 9; Figueroa 1888, 71-72.
} 
tomar"48. El Comité local de la CET\&L decide entonces, en su reunión del 9 de noviembre de 1899, que se pida la "reconsideración del acuerdo [del 30 de diciembre de 1898] ó el envío de los antecedentes al Tribunal Arbitral" 49 .

La solicitud correspondiente del 11 de noviembre de 189950, firmada por Eulojio Altamirano y Santiago A. Ossa, es una obra maestra en cuanto a su retórica y dramaturgia ideada para influir sobre la opinión pública, y además "ha sido mandado insertar en todos los diarios de la capital" según se quejó unos pocos días más tarde el concejal Herrera51. Frente a la Municipalidad y en especial frente a la opinión pública, el estilo adoptado en esta carta por el nuevo dúo que lideraba el Comité local de la CET\&L resulta ser más atractivo y convincente que el tono más directo y algo grosero utilizado por sus predecesores alemanes anteriormente. La "cercanía a la gente" de los dos nuevos representantes locales y el buen conocimiento que ellos tenían de las estructuras y prácticas culturales in situ, comprobaron ser de gran utilidad para la empresa operadora europea, ratificando lo que habían pensado al tomar la decisión de reestructurar su Comité local.

La argumentación de la solicitud presentada por Altamirano y Ossa comienza diciendo que la Empresa ya hubiera enviado en 1897 un ingeniero especialista, que desde julio de 1897 se llevarían a cabo observaciones diarias en el río Maipo y que las obras comenzarían aún este mismo año 1899 en diciembre. Además, aludieron a la buena reputación de los socios potentes en Europa:

La Ilustre Municipalidad sabe qué personas i qué sociedades son los dueños actuales del contrato; sabe que tienen la mas alta representacion en Lóndres i Berlín, por su fortuna i posicion social. Cuando una Sociedad tan respetable asegura su inquebrantable resolucion de dar inmediato principio a la ejecucion de las instalaciones en el Maipo, creo que la Ilustre Municipalidad no puede manifestar desconfianza, sobre todo si recuerda el modo cómo la ciudad entera reconoce i declara que ni ha visto ántes de ahora mejores materiales, ni hacer mayor gasto de enerjia en la conduccion de los trabajos encaminados a las construcciones contratadas ${ }^{52}$.

Además, la Municipalidad debería entender que la realización del sistema hidroeléctrico era aún más interesante para la empresa operadora que para la propia Municipalidad, ya que la compañía tendría que seguir la lógica del sector privado mientras que a la Municipalidad, como comprador de la electricidad a precios garantizados por contrato53, en última instancia, incluso le podría dar lo mismo cómo fuese producida la corriente: "Si lo que la Municipalidad arrendará [...] son caballos de fuerza, nada le importa que sean jenerados por el vapor o por las corrientes del Maipo; pero a la Empresa le importará mucho porque, en el primer caso, tendrá ménos utilidad que en el segundo"54.

Este razonamiento, que desde una perspectiva empresarial es bastante comprensible, parece sin embargo como una burla discursiva cuando se toma en cuenta que la empresa actúa sobre un doble fondo: de un lado postulando públicamente a la construcción de centrales hidroeléctricas y al mismo tiempo, clandestinamente, esperando tal vez poder seguir en el tiempo e implementar sus soluciones de catálogo.

Poco antes de terminar su carta, Ossa y Altamirano citan además las sumas de inversiones ya realizadas en el proyecto cuya cantidad debe haber impresionado mucho al público, y señalan

\footnotetext{
48 Citado en ACTAS MUNI SANTIAGO, Solicitud CET\&L, 11.11.1899, Tomo XI.2, 369; véase también ACTAS MUNI SANTIAGO, sesión 9a extraordinaria, 8.11.1900, Tomo XII.2, 453.

${ }^{49}$ ACTAS CL CET\&L, 32ª sesión, 9.11.1899, 75.

50 ACTAS MUNI SANTIAGO, solicitud CET\&L, 11.11.1899, Tomo XI.2, 369-374.

${ }^{51}$ ACTAS MUNI SANTIAGO, discurso Herrera, anexo al acta del 17.11.1899, Tomo XI.2, 376.

52 ACTAS MUNI SANTIAGO, solicitud CET\&L, 11.11.1899, Tomo XI.2, 371.

53 Los precios se fijan en el artículo 37 del contrato, el pago por trimestres vencidos en el artículo 44 (CET\&L 1914, 127-129).

${ }^{54}$ ACTAS MUNI SANTIAGO, solicitud CET\&L, 11.11.1899, Tomo XI.2, 373.
} 
además que "no hai en el contrato ni un artículo, ni una frase que autorice para decir que la fuerza eléctrica [...] ha de ser jenerada precisamente por las aguas del Maipo. Creemos que no se obtendría jamas una declaracion semejante de un Tribunal de Derecho" 55.

Entre las líneas queda entonces bastante clara la idea de tal vez no realizar el proyecto hidroeléctrico y, en un segundo plano, se desprende del texto el optimismo de la empresa en el caso de que se generase una disputa judicial sobre esta cuestión, asumiendo que la decisión caería a su favor, por lo cual la carta termina en la siguiente amenaza:

si US. creyera justo mantener el acuerdo, se habría producido una profunda desinteligencia en la manera de comprender el contrato, i en este caso a US. pedimos que se digne remitir los antecedentes al Tribunal Arbitral para que resuelva la cuestión de derecho que el acuerdo de US. ha promovido ${ }^{56}$.

En resumen, el mensaje principal de esta solicitud era: acepten por favor la energía térmica por el momento, y todo lo demás ya lo veremos más adelante (o nunca).

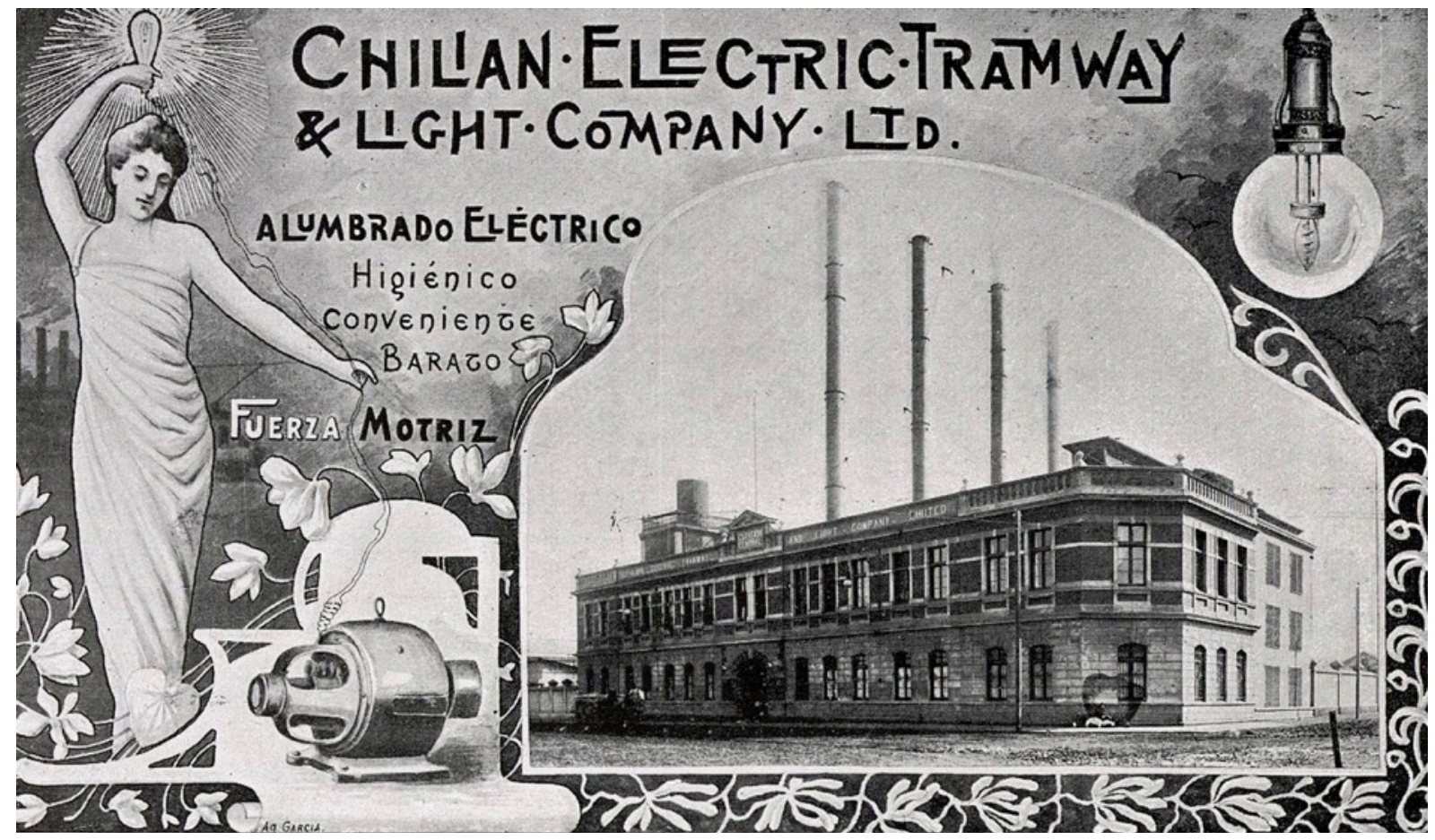

Figura 9: Publicidad de la central térmica Mapocho de la CET\&L. Fuente: Tornero 1903, 130.

En respuesta a esta solicitud de la compañía, el concejal Pedro A. Herrera, muy comprometido en este asunto, da un extenso discurso en la sesión de la Municipalidad del 17 de noviembre de 189957 en el cual expone, entre otras cosas, las contradicciones internas que contiene la carta. Recapituló que

al empezar su nota espresan [...]: "Desde los primeros pasos que se dieron para organizar la Compañía que representamos, se ha partido de la base invariable que la luz i la traccion serian jeneradas por fuerza hidráulica." Mas adelante dicen [...]: "Pero si no hubiera producido el acuerdo entre los deseos de US. i la resolucion de la Compañía, nos permitiríamos afirmar que no hai en el contrato ni un artículo ni una frase que autorice para decir que la fuerza eléctrica de que se sirva la Empresa ha de ser jenerada precisamente por LAS AGUAS DEL MAIPO.

\footnotetext{
55 ACTAS MUNI SANTIAGO, solicitud CET\&L, 11.11.1899, Tomo XI.2, 373.

56 ACTAS MUNI SANTIAGO, solicitud CET\&L, 11.11.1899, Tomo XI.2, 374.

57 ACTAS MUNI SANTIAGO, discurso Herrera, anexo al acta del 17.11.1899, Tomo XI.2, 375-378. Citados siguientes en páginas 376 y 376-377.
} 
Este comentario, dijo Herrera, dejaría muy claro cuál era la verdadera intención de la compañía, enfadándose con los señores Ossa y Altamirano quienes

han querido hacer juego con las palabras que aquí dije en la última sesion [...]. Sí, vuelvo a repetirlo; lo que la Corporacion tiene derecho a exijir es la instalacion hidráulica, porque así se cumple el contrato i al mismo tiempo le da garantía a la ciudad de que siempre tendrá fuerza motriz barata i suficiente para hacer traccion i alumbrado eléctricos a la espiracion de este famoso contrato. Con la instalacion a vapor no se cumple el contrato $n i$ se da esta garantía.

Un mes más tarde, durante el cual los concejales seguían debatiendo sin resultado si la Municipalidad debiese ceder o no el paso a la empresa, a mediados de diciembre Herrera formuló una "indicación para que se declarara que se desechaba la presentacion de los señores Altamirano i Ossa, en que han reclamado del acuerdo municipal que acordó no aceptar luz eléctrica para el alumbrado público, si no era jenerada por fuerza motriz"58.

Una vez más se produjeron debates acalorados entre los concejales sin que llegasen a un ningún resultado - una situación que no cambiaría mucho durante los próximos meses.

Recién en la sesión extraordinaria del 18 de abril de 190059, la Municipalidad decidió finalmente no dar lugar a la reconsideración pedida por la Empresa el 11 de Noviembre de 1899 siguiendo, sin debatir, una indicación del concejal Ojeda "para que se insistiera en el acuerdo por el cual se resolvió no aceptar luz eléctrica no jenerada por fuerza hidráulica; i desechar, en consecuencia, la reclamacion entablada contra ese acuerdo por los señores Eulojio Altamirano y Santiago A. Ossa." Ojeda propuso incluso rechazar, además del alumbrado, a la tracción eléctrica, formulando la siguiente indicación: "La Ilustre Municipalidad acuerda que el señor Alcalde comunique a la Empresa de Traccion i Alumbrado Eléctricos que no acepta la traccion si no es jenerada conforme al contrato, es decir, por fuerza hidráulica del rio Maipo."

Combatieron, pero el asunto quedó pendiente por no haberse agotado el debate. Al día siguiente siguió la discusión en una segunda sesión extraordinaria ${ }^{60}$, durante la cual el concejal Salinas expresó serias preocupaciones. Dijo que

miéntras mas meditaba sobre la indicacion formulada por el señor Ojeda, mayor gravedad le encontraba, pues se corria el peligro de que la ciudad se quedara sin traccion eléctrica, ni la jenerada por fuerza hidráulica, ni la jenerada a vapor, siendo esta última en todo caso preferible a la pésima actual traccion animal.

Además, expresó que él sí creía que la compañía iba a construir el sistema hidroeléctrico finalmente ya que, en su opinión, era también de su propio interés ya que a largo plazo este sistema le saldría más barato también a la compañía - "de modo que no hai peligro de que las instalaciones a vapor queden a perpetuidad."

Después del rechazo de su solicitud por la Municipalidad, la empresa finalmente concurrió al Tribunal Arbitral. Una sentencia61 diferenciada dio lugar a lo pedido y la Corte de Apelaciones confirmó ese fallo, según el cual, la Municipalidad tenía 15 días para hacer la designación de barrios "sin tomar en cuenta la fuerza que genere la electricidad"62. Al mismo tiempo, el tribunal postuló que la empresa

\footnotetext{
58 ACTAS MUNI SANTIAGO, sesión 167ạ ordinaria, 15.12.1899, Tomo XI.2, 401.

${ }^{59}$ ACTAS MUNI SANTIAGO, sesión 58ª extraordinaria, 18.4.1900, Tomo XII.1, 221-226. Citados siguientes de Ojeda en páginas 225 y 225-226.
}

${ }^{60}$ ACTAS MUNI SANTIAGO, sesión 59a extraordinaria, 19.4.1900, Tomo XII.1, 227-233. Citados siguientes de Salinas en página 230.

${ }^{61}$ ACTAS MUNI SANTIAGO, sentencia del Tribunal Arbitral, Tomo XII.2, 208-215.

62 Citado en ACTAS MUNI SANTIAGO, sentencia del Tribunal Arbitral, Tomo XII.2, 208. Véase además ACTAS MUNI SANTIAGO, cuenta del Tesorero Municipal, sesión 27a ordinaria 26.10.1900, XII.2, 384 у ACTAS MUNI SANTIAGO, resumen del Alcalde, sesión 9aㅡ extraordinaria, 8.11.1900, Tomo XII.2, 453. 
debería facilitar el suministro de electricidad por medio de la fuerza hidráulica después de un máximo de siete años a partir de la fecha. Con esta sentencia, dijo el concejal Arce en la sesión extraordinaria de la Municipalidad el 8 de noviembre de 1900 63,

no quedaba al Municipio otra cosa que proceder inmediatamente a la instalacion del alumbrado eléctrico, si bien debia dejarse constancia que en ese mismo fallo se reconoce a la Ilustre Corporacion el derecho de exijir al cabo de siete años que los servicios de traccion i de alumbrado eléctricos, sean jenerados por fuerza hidráulica del rio Maipo.

El concejal Herrera también expresó su alivio de que, después de todo, la "sentencia reconoce que debe exijirse [la fuerza hidráulica tomada del rio Maipo], i este asunto debe no olvidarse un momento en la discusion que se desarrolla, porque es la tabla de salvacion para el Municipio."

\section{Los sistemas hidroeléctricos de Valparaíso y Santiago}

Así fue que, tanto en Santiago como en Valparaíso, primero se construyeron y fueron puestos en servicio los sistemas termoeléctricos. En Santiago, la Bau-Kommission de la AEG informó al Comité local de la CET\&L en abril de 1900 que en la central térmica Mapocho "se hizo marchar con éxito la primera máquina de vapor" el día 3 del mismo mes. De las 7.000 toneladas de carbón que consumió la central Mapocho en su primer año de funcionamiento en 1900, sólo el 50 por ciento se obtenía de Chile - y más precisamente de Lota, de la mina ya mencionada perteneciente a doña Isidora Goyenechea de Cousiño. Dado que los depósitos de carbón nacionales, sin embargo, no presentaban la relación cantidad-calidad necesaria, el otro 50 por ciento tuvo que ser importado y llegó a Chile desde el otro lado del océano pacífico, y más precisamente de Australia, que en ese momento era todavía una colonia británica. El 2 de septiembre de 1900, algunos meses después del alumbrado, "autoridades del gobierno y de corporaciones del Estado" inauguraron en Santiago el servicio del tranvía eléctrico, y el 31 de octubre de 1900 ya estaban "en servicio 31 km de líneas sobre 28 km de vía"64.

Para el caso de Valparaíso, la revista berlinesa Elektrotechnische Zeitschrift en su edición del 25 de agosto de 1904 anunció "que la primera línea de ferrocarril eléctrico ya pronto estará lista y que parte del alumbrado público se estrenaría en octubre de 1904." La revista neoyorkina Street Railway Journal, por su parte, relató el 26 de noviembre de 1904 que la central térmica Aldunate estaría equipada con dos motores de 450 HP para fines de tracción y alumbrado. El servicio de los tranvías eléctricos se inauguró finalmente el 25 de diciembre de 1904, y al día siguiente El Mercurio de Valparaíso relató que la "fiesta organizada [...] por la Compañía de Traccion Eléctrica de Valparaíso [...] resulto, bajo todos conceptos, magnifica" 65 .

En cuanto a los sistemas hidroeléctricos, fue la DUEG/CATE quien a partir de 1905 para Santiago y de 1906 también para Valparaíso se hizo cargo de su construcción. Con ello, empezó su expansión como holding a través del continente, y probablemente fue por esta misma razón que fue capaz de proporcionar la financiación necesaria para realizar las

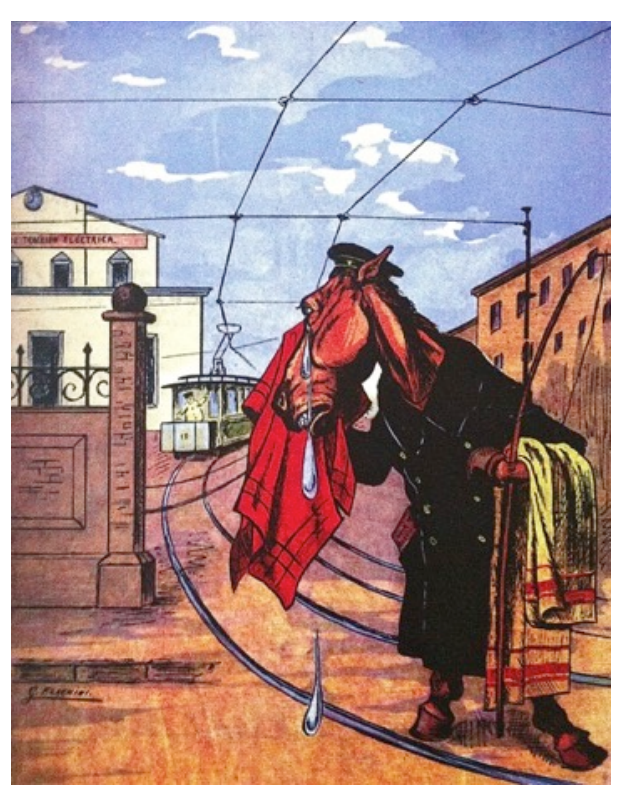

Figura 10: Despedida del tranvía de sangre. Caricatura de G. Flachini. Fuente: Revista "Sucesos", N 125, 11 de enero de 1905.

\footnotetext{
${ }^{63}$ ACTAS MUNI SANTIAGO, sesión 9a extraordinaria, 8.11.1900, Tomo XII.2, 451-457. Citado siguiente de Arce en página 453, él de Herrera en página 457.

${ }^{64}$ Carta de la Bau-Kommission en ACTAS CL CET\&L, 52a sesión, 5.4.1900, 111; ACTAS CL CET\&L, 28a sesión, 12.10.1899, 68; ACTAS CL CET\&L, 30ª sesión, 26.10.1899, 72; ACTAS CL CET\&L, 65aㅗ sesión, 4.11.1900, 132-133; Castillo 1994, 28-29.

65 “Elektrische Strassenbahn Valparaiso A.-G., Berlin”. Elektrotechnische Zeitschrift. Berlín, 1904, Heft 34, 25.8.1904, p. 754; "The Valparaiso Tramways". StreetRailway Journal. Nueva York, 26.11.1904, p. 948; "La inauguración del servicio de tranvías eléctricos en Valparaíso". El Mercurio de Valparaíso. 26.12.1904, p. 5.
} 
obras de tal envergadura, incluyendo la compra de extensas tierras, estudios técnicos y el desarrollo de nuevas soluciones técnicas. Es probable que las dos empresas operadoras CET\&L y ETEV, que actuaban más bien a nivel local, no hayan sido capaces de cubrir tales gastos. Con el nuevo mando por la DUEG/CATE, la construcción de las dos centrales hidroeléctricas y sus redes correspondientes empezaron a tomar forma y el sistema de Valparaíso finalmente fue puesto en servicio incluso unos pocos años antes que el de Santiago, a pesar del hecho de que los contratos en Valparaíso se habían firmado unos cinco años más tarde. Después de la central Chivilingo de Lota, la central hidroeléctrica El Sauce de Valparaíso resultó ser entonces el segundo pionero hidroeléctrico en Chile. Pamela Fuentes, la directora del Museo Histórico de Placilla, comunidad a la cual pertenece la central, subraya que El Sauce era "la primera central hidroeléctrica de uso público en Chile" y además un ejemplo temprano del uso de la corriente alterna en el país66. La red del sistema hidroeléctrico de la CET\&L en Santiago, cuando éste fue puesto en servicio finalmente en 1909-1910, fue de mayor tamaño que la de Valparaíso ya que, aparte de Santiago, englobó también a su ciudad vecina de San Bernardo. Una vez puestas en marcha las centrales hidroeléctricas de ambas ciudades, las dos centrales térmicas, Aldunate en Valparaíso y Mapocho en Santiago, que datan de la primera fase de la electrificación alemana en la región capitalina de Chile, se mantuvieron activas.

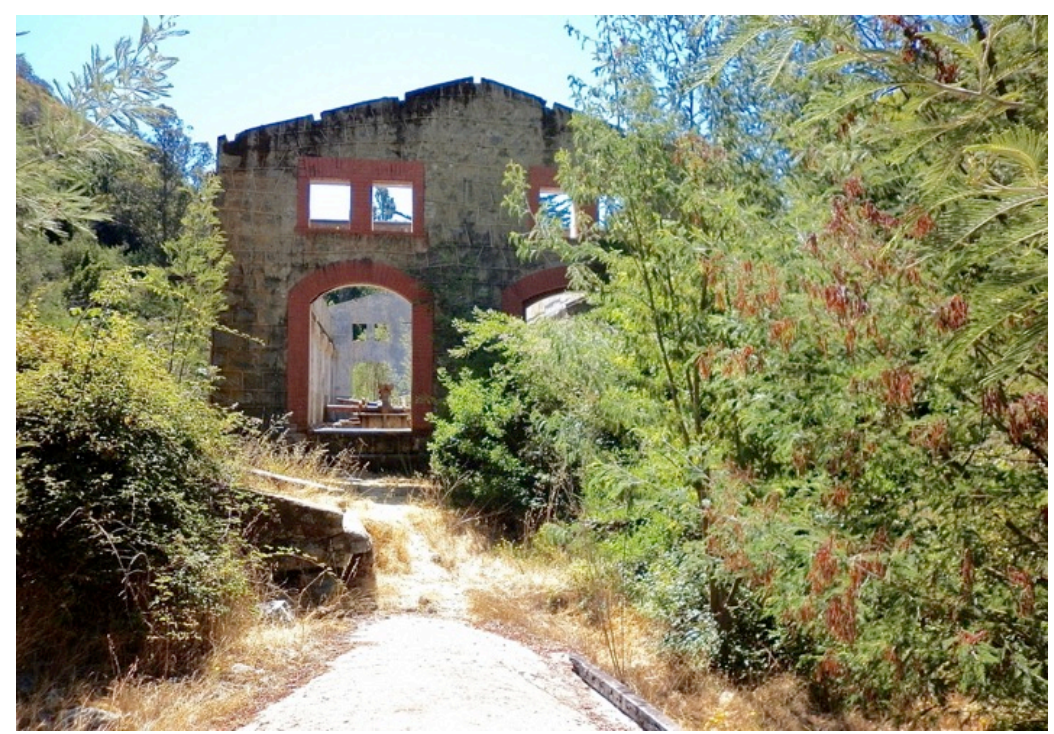

Figura 11: Estado actual de la central hidroeléctrica El Sauce en Placilla, comunidad de Valparaíso. Fuente: Foto Marion Steiner, 26 de diciembre de 2014.

\subsection{Valparaíso: central El Sauce y tranque La Luz}

En Valparaíso, a unos ocho kilómetros al sur del centro de la ciudad, en la Cordillera del Mar, se construyó una central hidroeléctrica de tipo embalse llamada El Sauce, denominada así por el nombre del fundo en el cual fue construida (estado de conservación actual: central en ruina, embalse existente pero amenazado por un proyecto inmobiliario poco transparente, presa sin manutención desde hace décadas). Su recurso hídrico provenía del lago Peñuelas, aprovechando un salto de unos $900 \mathrm{ft}$ para generar alrededor de 3.000 caballos de fuerza. La planta central estaba conectada con una estación secundaria ubicada en el centro de la ciudad por dos líneas de transmisión aéreas de 9,5 kilómetros de longitud. Al llegar al cerro de la Mariposa las líneas se transformaban en líneas subterráneas en la casa de transición, de donde iban a la estación secundaria que, al igual que la casa de transición, sigue funcionando hasta el día de hoy y dista de ahí 350 metros. El 25 de agosto de 1904, la revista berlinesa Elektrotechnische Zeitschrift informó que las instalaciones hidroeléctricas iban a ser completadas para ser puestas en servicio hasta octubre de 1905. Se produjeron algunos retrasos, y el cambio de la generación a vapor a la hidroeléctrica se realizó finalmente el 4 de mayo de $1906^{67}$. De la pequeña fiesta de inauguración, El Mercurio de Valparaíso relataba al día siguiente:

\footnotetext{
66 Fuentes 2014, 16.

67 “The Valparaiso Tramways”. StreetRailway Journal. Nueva York, 26.11.1904, p. 948; Lynch 1908, 354; Flores 2000, 108-109; “Elektrische Strassenbahn Valparaiso A.-G., Berlin". Elektrotechnische Zeitschrift. Berlín, 1904, Vol. 34, 25.8.1904, p. 754.
} 
En presencia de la concurrencia aludida, se procedió [...] a paralizar los motores a vapor, que habían abastecido durante largo tiempo de energia eléctrica a Valparaiso, y, mientras los dinamos proseguían su eterna y vertiginosa carrera, alimentados por acumuladores, se les conectó definitivamente con los cables de transmisión de fuerza de Peñuelas.

Esta operación de tanta trascendencia, se efectuó del modo mas fácil y sencillo que es posible imaginar, y sin que los dinamos disminuyeran por un momento sus rápidos giros. Era difícil formarse el concepto de que, con tan solo esa operación, una nueva y poderosísima corriente de fuerza y energías se desparramaba por Valparaiso, como un factor mas de progreso y de desarrollo fabril ${ }^{68}$.

En aquel momento, la central El Sauce ya tenía una capacidad de 3.600 caballos de fuerza y suministraba a 33 kilómetros de líneas de tranvía. A partir de marzo de 1907, con el motivo de aumentar la fuerza motriz, fue ampliado de manera significativa el embalse, el cual al principio solo contaba con un "simple ataje" de 80 metros de longitud y una altura media de 9 metros. En la ampliación se le proporcionó una nueva presa de 125 metros de longitud y una altura de 30 metros, capaz de agarrar $4.000 \mathrm{~m}^{3}$ de agua. En 1908, entró en pleno servicio El Sauce 69.

Al lado de la central se construyó además un pequeño asentamiento de unas pocas casas habitadas por el ingeniero y los obreros de la planta que debían tomar residencia allí debido a que la central se situaba al fondo del valle de lo que antes era el fundo El Sauce, y por lo tanto, estaba muy aislada del centro de Valparaíso y las demás poblaciones del área. Otro asentamiento fue erigido para el ingeniero y los obreros de la parte hidráulica del sistema que tomaron residencia en la parte de arriba, en el borde del embalse (o "tranque" en chileno), el cual fue muy acertadamente bautizado: el tranque La Luz. El asentamiento de la central sirvió, primero, como alojamiento para los trabajadores cuando aún estaba todavía en construcción la nueva presa, pero desde el principio fue planeado de tal manera que, al terminarse las obras, pudiese ser ajustado con poco esfuerzo a las necesidades de sus residentes permanentes ${ }^{70}$.

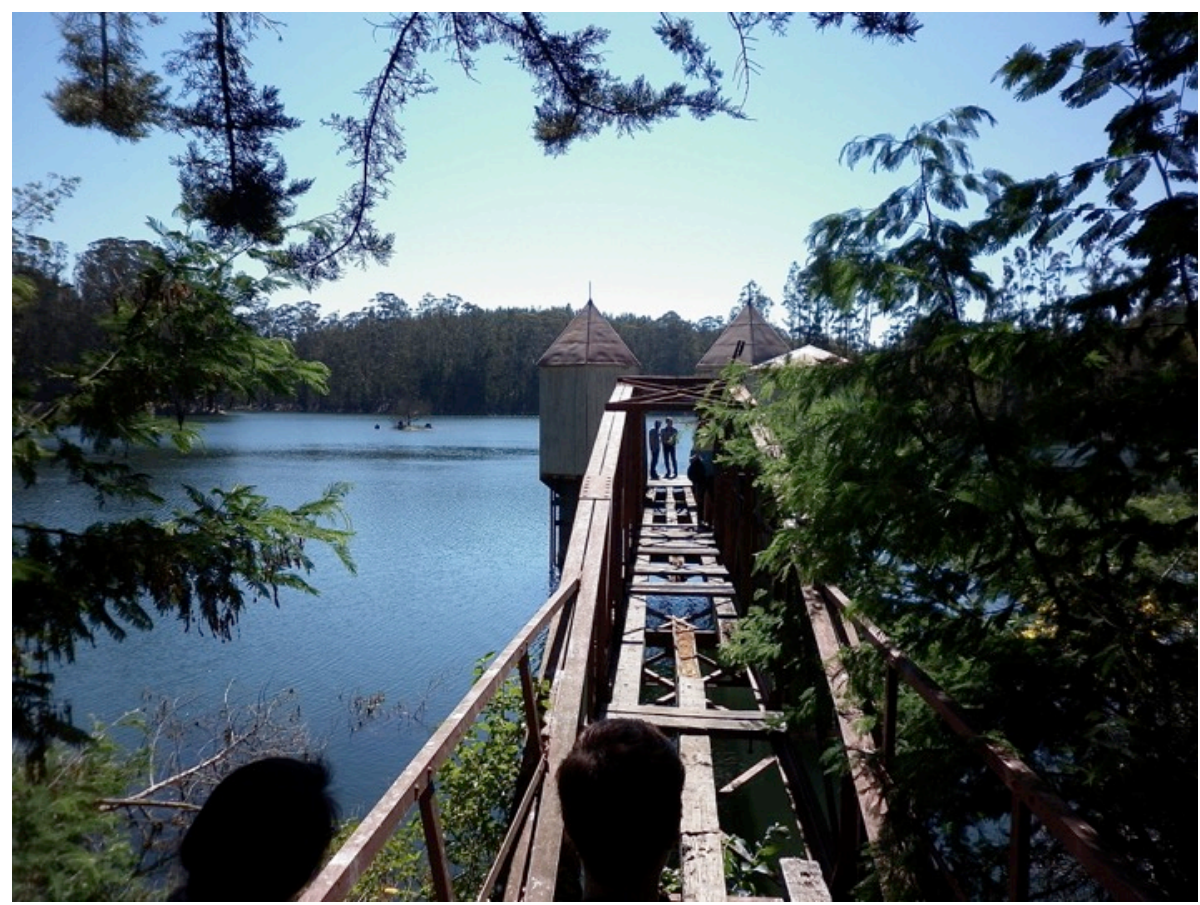

Figura 12: Las torres de válvula en el tranque La Luz. Fuente: Foto Marion Steiner, 26 de diciembre de 2014.

68 “La Traccion Eléctrica en la parte plana: Inauguracion del servicio”. El Mercurio de Valparaíso, 5.5.1906, pp. 4-5.

69 Jacob-Wendler 1982, 170; Lynch 1908, 352-355, 358; Flores 2000, 106.

70 Fuentes 2014, 14-15. Véase también Lynch 1908 y Deulofeu 1999. 
En la ciudad de Valparaíso, donde la integración de los barrios más poblados en los cerros Barón y Playa Ancha en la red del tranvía eléctrico era una condición importante del contrato firmado entre la ciudad y la empresa, la CTEV construyó aparte de las líneas de tranvía correspondientes y como parte íntegra del sistema multimodal de transporte público típico de Valparaíso, también el primer ascensor enteramente eléctrico de la ciudad. El Ascensor Barón, propiedad de la compañía alemana de tranvías, fue el elemento clave que conectó la línea de tranvías manejada por la CTEV en el mismo cerro Barón con el "Plan", la parte plana de la ciudad. A partir de la inauguración de este ascensor, los trabajadores residentes en el cerro Barón pudieron hacer en transporte público todo el trayecto desde sus casas en el cerro hasta sus respectivos lugares de trabajo, los cuales en su mayoría se encontraban en ese entonces en el barrio Almendral y cerca del puerto, en el Plan de la ciudad71.

\subsection{Santiago: central La Florida y canal La Luz}

En Santiago, a unos 12 kilómetros de distancia del centro urbano histórico y al pie de la Cordillera de Los Andes, se construyó una central hidroeléctrica de pasada, llamada La Florida, y un nuevo canal, llamado canal de La Luz (ambos siguen en operación) que utilizaban las aguas del tradicional canal de riego San Carlos. Debido a su ubicación aislada aquí también se construyeron, junto a las instalaciones técnicas, casas para el director y los empleados de la central (aún se conservan). La central La Florida fue conectada por cables subterráneos con la subestación Victoria (conservada, utilizada por la empresa eléctrica como oficinas y almacenes) en Santiago y desde aquí, la electricidad se repartía a las otras tres subestaciones de la ciudad: Mapocho (conservada, en operación original), Villavicencio (desaparecida) y Unión Americana (conservada, utilizada como almacén por una empresa electro-técnica), por túneles de cables de 2 metros de altura que se construyeron por debajo de las calles de la ciudad y se han preservados hasta el día de hoy a pesar de los terremotos típicos de la región. Aparte de la conexión por cables subterráneos desde La Florida hacia Santiago, una línea aérea suministraba la ciudad vecina, San Bernardo. Este sistema entró en pleno funcionamiento en 1910, y luego continuó su expansión. La construcción de la central La Florida se basaba en una concesión de agua de 20.000 caballos de fuerza, instalándose primero una capacidad de $12.000 \mathrm{~kW}$, la cual fue aumentada invirtiendo aproximadamente 6 millones de Marcos alemanes para alcanzar 16.000 caballos de fuerza hacia finales de 1909. Hacia 1913, finalmente, se incrementó por otros 4.000, llegando así a los 20.000 caballos de fuerza72.

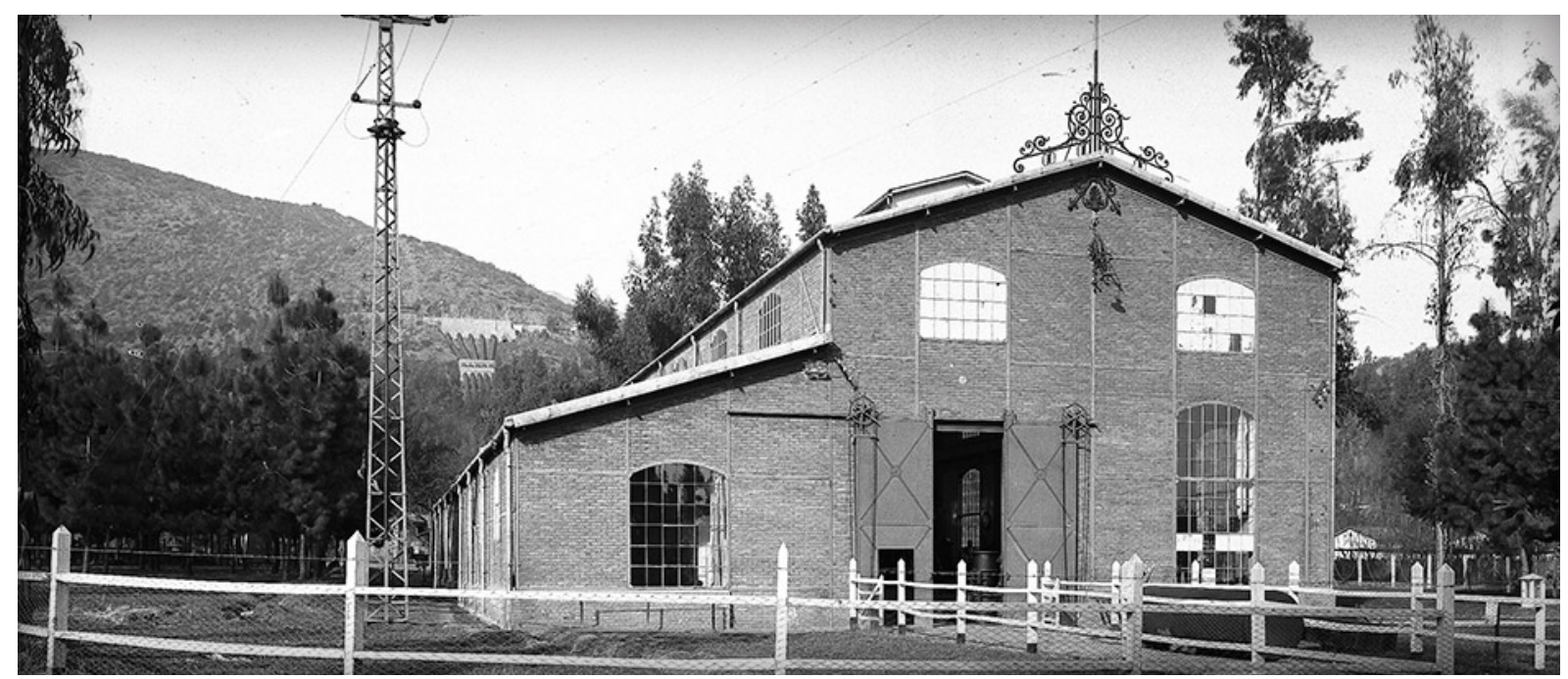

Figura 13: Central hidroeléctrica La Florida, en las afueras de Santiago de Chile. Fuente: lugaresdeciencia.cl

Mientras que la central hidroeléctrica La Florida y las cuatro subestaciones en la ciudad de Santiago eran propiedad de la DUEG/CATE, "la gran red de cables para alumbrado, fuerza motriz y tranvías" y la "instalación auxiliar a vapor en la calle Mapocho" pertenecían a la CET\&L, según consta en

71 Municipalidad de Valparaíso 1902, 999-1000; Ugarte Yávar 1910, 76-86; A.E.G.-Zeitung 1906/1907 No. VII, enero 1907, p. 182 [SDTB, Archivo AEG, Berlín, sig. I.2.060 ZS 11764]; http://patrimonio-urbano.cl/index.php/arquitectura/ publica/25-breve-historia-del-ascensor-baron [accedido 16.1.2017].

72 CATE 1916, 20; Nazer et al. 2005, 30; Jacob-Wendler 1982, 168.

(C) Labor \& Engenho, Campinas [SP] Brasil, v.11, n.4, p.446-476, out./dez. 2017. 
un folleto de la DUEG/CATE publicado en 1916. Esta situación de propiedad mixta entre una empresa berlinesa y otra registrada en Londres, que probablemente sólo se generó porque los socios financieros más importantes para el negocio en Santiago estaban basados en el centro financiero mundial de la época, iba a tener una importancia imprevista años más tarde. Al comenzar la Primera Guerra Mundial, los británicos intentaron influenciar directamente en los negocios de la CET\&L, y si bien no tenían acceso a la fuente de alimentación del sistema eléctrico, ya que ésta estaba en manos del holding berlinés, sí que lograron complicarle mucho su trabajo a la DUEG/CATE mediante una guerra económica cuyos boicots económicos y cortes del transporte y la comunicación afectó a todas las empresas alemanas que trabajaban lejos de su patria. La CET\&L por su parte, como empresa operadora local, tenía la suerte de estar mucho más vinculada con los políticos y diplomáticos ingleses en Chile y cuando empezó la guerra, gracias a este tipo de amistades personales, disfrutó aún durante bastantes años de una protección política. No obstante, en junio de 1917 finalmente, la CET\&L también fue incluida en la lista negra de los ingleses ${ }^{73}$.

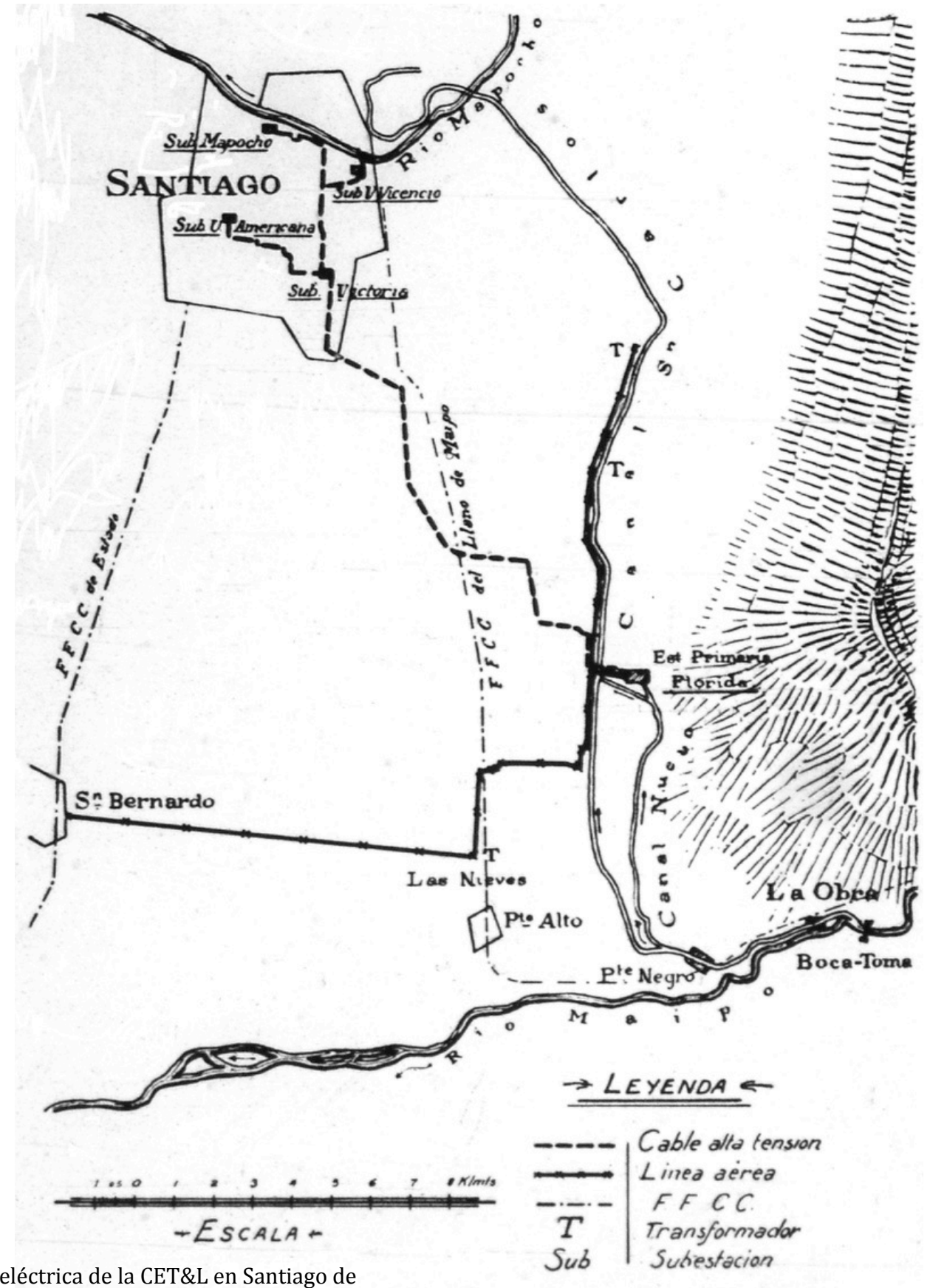

Figura 14: La red hidroeléctrica de la CET\&L en Santiago de Chile, alrededor de 1910. Fuente: CATE 1916, 2.

${ }^{73}$ CATE 1916, 18, 20; Couyoumdjian 1986, capítulo VII, 137-159. 


\section{La AEG y sus amigos suizos}

Tomando en cuenta el gran escepticismo que Emil Rathenau puso de manifiesto durante mucho tiempo frente al "fantasma de la fuerza motriz", es probable que la tenacidad con la cual los dos municipios chilenos, alrededor del 1900, insistieron en su implementación, haya hecho una diferencia importante y provocado, en última instancia, que las empresas constructoras y financieras alemanas efectivamente realizaran la construcción de los sistemas hidroeléctricos en Santiago y Valparaíso. Quizás, si no hubiesen insistido las Municipalidades, se hubiesen demorado aún más tiempo en empezar las obras; y considerando que poco tiempo después empezó la Primera Guerra Mundial, este nuevo contexto geopolítico sin lugar a dudas hubiese imposibilitado por completo la implementación del proyecto. El escenario que tanto les preocupaba a muchos de los concejales de Santiago, que la empresa fabricante y la empresa operadora pudiesen desistir del proyecto hidroeléctrico una vez que estuviese funcionando el sistema térmico, aparece hoy, bajo todos los conceptos, bastante realista.

Cuando en 1905/1906, la DUEG/CATE se convirtió en la entidad responsable de la construcción de los sistemas hidroeléctricos en Santiago y Valparaíso, encargó, en gran parte, a otras empresas constructoras aparte de la AEG con la ejecución de las obras. Por un lado, la AEG probablemente no tenía en este momento los conocimientos técnicos y la experiencia necesarios para construir sistemas globales de aprovechamiento de la fuerza motriz del agua. Por otro lado, la DUEG/CATE empezaba a funcionar a partir de estas fechas como un gran holding el cual, como ya se ha dicho, desde el principio hasta su disolución en 1920 fue liderado por la Deutsche Bank. A través de ésta existían contactos íntimos no sólo con la AEG, sino que también con la empresa Siemens, quien también recibía encargos de la parte de la DUEG/CATE en Chile. En Santiago por ejemplo, Siemens suministraba algunos de los generadores para la central La Florida, mientras que con el diseño general de los sistemas hidroeléctricos la DUEG/CATE encargó a la compañía suiza Escher, Wyss \& Cie. de Zúrich - una empresa amiga del grupo AEG-Deutsche Bank que suministró también los generadores para El Sauce y que estuvo además a cargo del diseño de la propia central, según dice Pamela Fuentes del Museo Histórico de Placilla el cual, junto con el Centro Cultural Placilla, lucha para la conservación y el estudio patrimonial de la central El Sauce, entre otras $\operatorname{cosas}^{74}$.

En cualquier caso, las empresas constructoras suizas contaban con una experiencia mucho más larga en cuanto a la construcción de sistemas globales de aprovechamiento de fuerzas hidráulicas, y la AEG mantenía contactos íntimos con la mayoría de ellas: con la MFO ya había cooperado en la Exposición de Frankfurt de 1891, y la MFO a su vez estaba estrechamente vinculada con Escher, Wyss \& Cie., con la cual realizó, por ejemplo, la electrificación de la ciudad de Zúrich que inauguró su primera central hidroeléctrica el 1 de enero de 1893. Otra empresa constructora suiza que pertenecía a la esfera de influencia del grupo AEG era Brown Boveri \& Cie (BBC), con cuya fundación el 2 de octubre de 1891, los dos ingenieros de la MF0 que habían contribuido de manera significativa al éxito de la exposición de Frankfurt, sellaron su independencia de la casa matriz poco tiempo después del cierre de la exposición. El capital necesario para su empresa start-up lo puso el industrial de seda Conrad Baumann de Zúrich quien cumplió así una promesa de crédito que había dado a Boveri un año antes de que éste se casara con su hija. Curiosamente, la mayoría de las acciones de la BBC fueron adquiridas en 1904/05 por la AEG que las mantuvo hasta $1915^{75}$.

Pero el grupo AEG-Deutsche Bank no solo cultivó estrechos vínculos con Suiza en cuanto a las empresas constructoras - también hizo lo mismo en el sector de los bancos. Ya en la creación de la DUEG/CATE en 1898 en Berlín habían participado, aparte de los actores que mencionamos en la primera parte del presente texto, dos institutos financieros con sede en Zúrich: la Schweizerische Kreditanstalt (SKA) con un $62 / 3$ por ciento, y la Bank für Elektrische Unternehmungen (nombre corto: Elektrobank) con un $31 / 2$ por ciento. Este último, la Elektrobank, se había creado por iniciativa de Emil Rathenau y Georg von Siemens en Zúrich en 1895, es decir, tres años antes de la DUEG/ CATE. Fue concebido como holding e instituto de financiación especial para los negocios eléctricos del grupo en el sur de Europa: "primero se hizo cargo de la mayoría de las acciones de las compañías eléctricas genovesas [...]; a continuación, le compró a la AEG sus empresas operadoras en Sevilla, Barcelona y Bilbao. Pero solo dirigían estas empresas hasta que éstas fuesen establecidas organiza-

\footnotetext{
74 Jacob-Wendler 1982, 170; Lynch 1908, 353; Fuentes 2014, 12.

75 Gugerli 1996, 101.
} 
tiva, técnica y financieramente y capaces de mantenerse por fuerza propia, es decir, hasta el momento en que sus acciones estaban maduras y podrían ser emitidas en el mercado". La DUEG/CATE funcionaba de la misma manera pero, a su vez, se centró en el negocio de América del Sur76.

La mayoría de las acciones de la Elektrobank de Zúrich poseía el grupo AEG-Deutsche Bank. Sin embargo, entre sus fundadores figuraba también un grupo financiero suizo que fue liderado por la Schweizerische Kreditanstalt (SKA)77, la cual, tres años más tarde, participó además en la fundación de la DUEG/CATE. La SKA fue fundada en 1856 por Alfred Escher (1819-1882), uno de los magnates suizos más conocidos del siglo XIX, quien tenía también una reputación importante como hombre político y de negocios. Con la SKA había convertido a Zúrich en el centro bancario y económico líder de Suiza, y además había participado en la fundación de la reconocida universidad técnica de Zúrich, la ETH, y de la Compañía del Ferrocarril de Gotthard la cual, entre 1872 y 1882, construyó el túnel del mismo nombre por debajo de los Alpes.

Cabe señalar que Suiza en general, y también Bélgica, eran particularmente interesantes como sedes para los nuevos holdings creados a finales del siglo XIX y principios del XX, porque el derecho comercial de ambos países "permitió la emisión de bonos mucho más grandes que la ley alemana". Esto, según pusieron de manifiesto los historiadores de economía Hausman, Hertner y Wilkins en 2008, permitía que los bancos y empresas alemanes "obtuvieran 'control ejecutivo [...] con poca inversión de capital propio, el capital real siendo suministrado por obligaciones y bonos." Actuando desde las sedes de sus holdings en Suiza o Bélgica, los bancos alemanes podían entonces acceder más fácilmente al mercado de capital extranjero que desde Alemania, reunir capital francés y alemán y, además, aprovechar la posición políticamente neutral de Suiza78.

Si se tiene en cuenta lo que ya dijimos en la primera parte del presente ensayo: que la empresa de Siemens recién fue convertida en sociedad anónima en 1897 mientras que la AEG ya desde 1895 con la Elektrobank y desde 1898 con la DUEG/CATE ya actuaba soberanamente en el mercado financiero mundial; se aclara una vez más la enorme diferencia entre el primer Unternehmensmanager (gestor de empresas) de Alemania Emil Rathenau y el empresario más tradicional y de familia Werner Siemens. Para la era inminente del capitalismo financiero mundial moderno, Rathenau fue un precursor importante y se puede considerar el primer representante de un nuevo tipo de actores.

\section{Derrotas amargas en España y Chile}

Con los sistemas hidroeléctricos de Valparaíso y Santiago ambos en pleno funcionamiento en 1910, es interesante contrastar nuevamente el caso chileno con él de España - y el destino que iba a tener el negocio de la AEG en Cataluña es particularmente revelador. Ya hemos visto cómo, en 1903, Emil Rathenau rechazó el negocio hidroeléctrico que le fue ofertado en el Pirineo. Unos pocos años después, la AEG en Barcelona se vio confrontada a la competencia del ingeniero norteamericano Frederick Stark Pearson (1861-1915), quien ya había organizado la Mexican Light and Power Co.79, tenía además proyectos en Brasil, y en 1907 construyó la primera central hidroeléctrica en las cataratas del Niágara. Para financiar sus ambiciones en Cataluña, Pearson había creado ahora "no sólo una empresa, sino todo un grupo de sociedades", según puso de manifiesto Javier Loscertales en su tesis doctoral co-supervisada por Peter Hertner sobre Las inversiones alemanas en España, 1870-1920, la cual se presentó en la universidad de Frankfurt am Main y solo se ha publicado en alemán. Según él, a partir de 1911, las empresas de Pearson compraron "todo lo que tenía que ver con 'electricidad' en este país y convulsionaron el mundo financiero catalán como un terremoto" 80 .

\footnotetext{
76 Seidenzahl 1984, 170; Pohl 1988, 143.

77 Pohl 1988, 143.

78 Hausman et al. 2008, 96 (cita: British Electrical and Allied Manufacturers' Association. Combines and Trusts in the Electrical Industry: The Position in Europe in 1927. Nueva York: Arno Press, 1977 [1927]); Pohl 1988, 143.

${ }^{79}$ A esta empresa, Wernher, Beit \& Co. habían vendido en 1906 (el año en que murió Alfred Beit) los tranvías eléctricos de la Ciudad de México a un precio igualando a 44 millones de Marco (Jacob-Wendler 1982, 315).

80 Loscertales 2002, 196
} 
La nueva Barcelona Traction Light \& Power Co. Ltd. de Pearson, que ya pronto fue llamada "La Canadiense" debido al lugar de su registro, tenía previsto "nada menos que provisionar a todo el mercado catalán con el 'carbón blanco', señala Loscertales. La primera empresa operadora residente en Cataluña que compró fue precisamente la Barcelonesa del grupo AEG-Deutsche Bank. Tenía una importancia estratégica para Pearson "debido a sus grandes instalaciones, la red de cables ya existente que se extendía por toda Barcelona y porque las estaciones de energía hidráulica necesitaban una central auxiliar a vapor" en el centro de la ciudad. Mientras tanto, relata Loscertales, los actores berlineses por su parte también habían reconocido que la Barcelonesa "ya no podría haber sido competitiva, como resultado de la electricidad más barata generada por la fuerza del agua". En la asamblea general de la Elektrische Licht und Kraftanlagen AG de 1911, se informó que la Barcelona Traction "constituye una seria competencia porque puede vender energía eléctrica generada por el agua del Pirineo a precios más bajos en Barcelona” 81 .

La venta de la Barcelonesa a Pearson resultó, no obstante, un "brillante negocio" para la AEG a pesar del hecho de que las acciones no se pagaron en efectivo sino que en acciones de la Barcelona Traction, con lo cual la Deutsche Bank tuvo que adelantar el dinero para los otros socios, lo que no le gustó mucho ni a Emil Rathenau ni a Arthur Gwinner. Sin embargo, el caso demuestra también cómo la AEG y sus financieros fueron expulsados del mercado eléctrico catalán a raíz de las actividades concurrentes del consorcio montado por el norteamericano Pearson y, por otra parte, por la subestimación sensacional de Emil Rathenau en cuanto al potencial futuro del nuevo tipo de tecnología que representaba el aprovechamiento de la fuerza motriz del agua. Contrariamente a las afirmaciones de algunos autores, que la supremacía de la AEG en la electrificación de España hubiese persistido hasta la Primera Guerra Mundial, Javier Loscertales demuestra en su tesis doctoral que de hecho ya la había perdido varios años antes. La única empresa operadora de la AEG en España que permaneció bajo su control hasta que se iniciara la guerra y también después, fue la Sevillana, donde Rathenau en 1904/05 había tratado de impedir por todos los medios, y finalmente sin éxito, la construcción de una central hidroeléctrica por la nueva Compañía Hidroeléctrica del Guadiaro82.

El éxito rotundo que tuvo Pearson en Cataluña se explica también por el hecho de que, muy contrariamente a las estrategias que perseguía la AEG, lo que Pearson planteaba a los catalanes era un verdadero proyecto de desarrollo territorial, de gran escala y multisectorial según comenta Joan Roca, el actual director del Museo de Historia de Barcelona: "Pearson concebia el negoci català en termes globals de proveïment d'energia, desenvolupament del transport elèctric i promoció immobiliària més enllà de Collserola." Dentro de este contexto es sumamente interesante señalar que la empresa Ferrocarriles de Catalunya, la cual construyó las primeras líneas férreas en la década de 1910 para conectar las actividades industriales en Barcelona con las de su hinterland, formaba parte integral del propio consorcio de Pearson 83 .

Al comenzar la Primera Guerra Mundial el precio del carbón aumentó de una manera que habría sido inimaginable anteriormente para la AEG, la cual se había focalizado entonces en la termoelectricidad, modificándose el escenario completamente. Muchas rutas del comercio marítimo se cortaron y el bloqueo económico de los ingleses contra los barcos alemanes impedía, entre otras cosas, el transporte de carbón tan necesario para alimentar a las centrales térmicas. Este nuevo contexto geopolítico alteró fundamentalmente la manera del cómo calcular y evaluar las potencialidades de la fuerza motriz del agua. Como consecuencia, y a partir de aquel momento, la AEG también se puso a invertir considerablemente en el uso de la hidroelectricidad, como por ejemplo lo vemos en Sevilla en 1917. A pesar de ello, insiste Loscertales, la energía hidroeléctrica ya en el año 1910 representaba una "alternativa muy seria a la operación a vapor" en lugares "donde las condiciones geográficas lo permitieron" 84.

\footnotetext{
${ }^{81}$ Loscertales 2002, 195-197 (cita ETZ 1911, p. 1311).

82 Loscertales 2002, 149, 156, 197-198.

83 Roca 2012, 284; Armengol 2013, 191-193; véase también Capel 1994, vol. 2.

84 Loscertales 2002, 177, 195.
} 


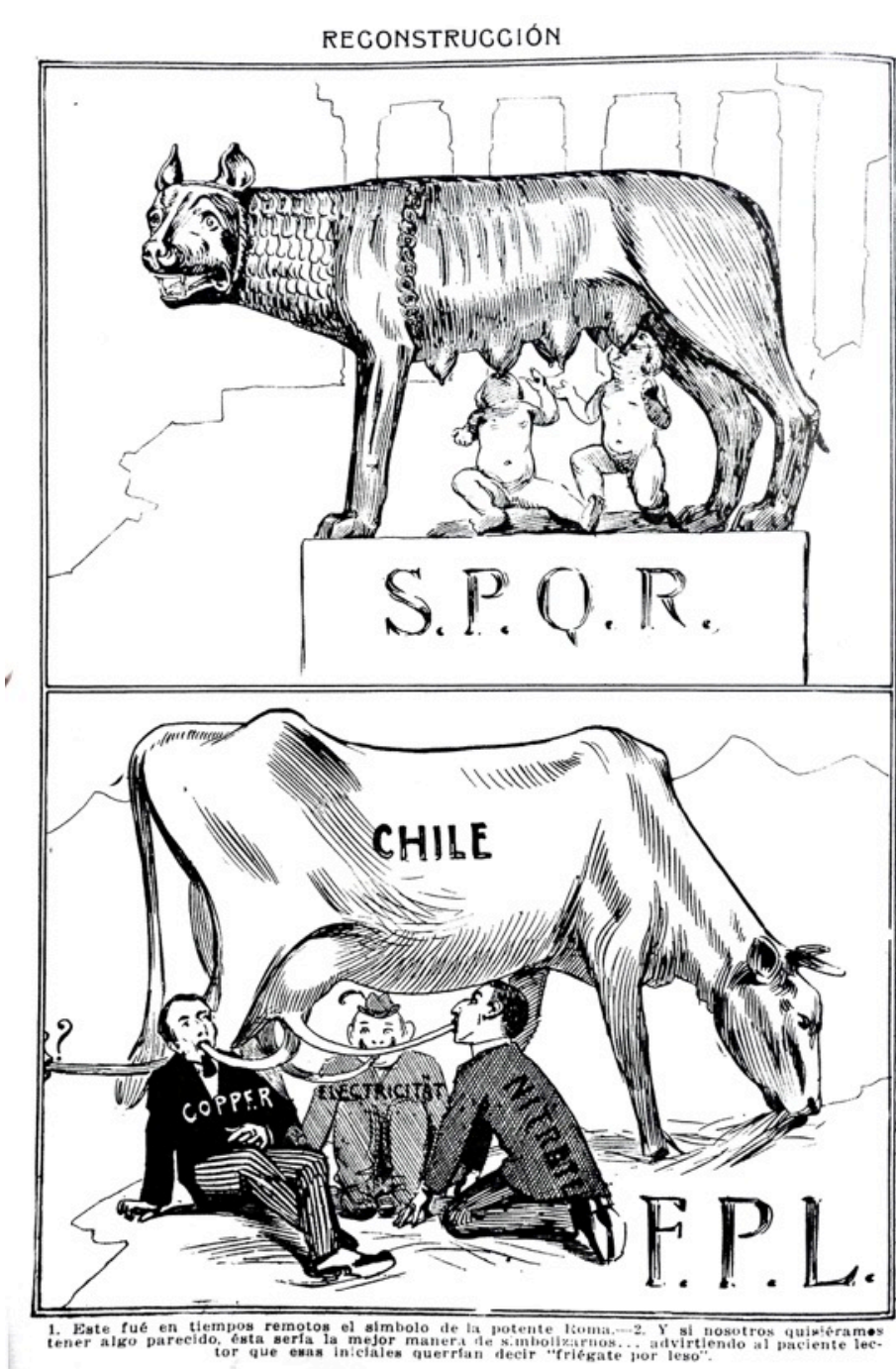

Figura 15. Caricatura chilena. El texto abajo dice: "1. Este fue en tiempos remotos el símbolo de la potente Roma. - 2. Y si nosotros quisiéramos tener algo parecido, ésta sería la mejor manera de simbolizarnos... advirtiendo al paciente lector que esas iniciales querrían decir 'friégate por leso.'” Fuente: Revista “Zig Zag”, edición del 30 enero de 1915.

portancia a los británicos, como señala también Ricardo

En Chile, por el contrario, el final de la electrificación alemana sí que coincidió con la derrota militar del Imperio Alemán en la Primera Guerra Mundial. Inmediatamente después de la guerra el propio gobierno británico confiscó a la CET\&L registrada en Londres. Tras un breve pero intenso debate con la Municipalidad de Santiago sobre una nacionalización de la empresa operadora, el gobierno inglés finalmente la vendió a la firma británica Samuel Pearson \& Son Ltd. 85 (estos Pearson británicos no deben ser confundidos con el ingeniero norteamericano Frederick Stark Pearson quien, en ese momento, incluso ya estaba muerto). En 1921, S. Pearson \& Son adquirieron además una empresa eléctrica chilena competidora de la CET\&L que suministraba áreas importantes en la región de Santiago, y la fusionaron con la CET\&L, creando así la Compañía Chilena de Electricidad (Chilectra). En los años siguientes, dentro de un contexto de modernización urbana de gran envergadura, los Pearson británicos realizaron inversiones en la renovación y ampliación del sistema eléctrico en Santiago y sus alrededores, tan importantes que incluso hasta el día de hoy comúnmente se piensa en Chile que la electrificación del país tuviera raíces inglesas. No obstante, la "ilusión inglesa" en Chile, como lo suele llamar Peter Hertner, duró muy poco tiempo y se terminó en 1928 con la venta de Chilectra a unos inversores estadounidenses. Los norteamericanos, en estos momentos, ya habían tomado pie firme en Chile y sobrepasado en imBretaña durante la primera Guerra Mundial y la postguerra, 1914-1921.

La DUEG/CATE se disolvió en 1920 y se vendió a un grupo multinacional, el cual continuó los negocios del ex-holding alemán bajo el nombre de Compañia Hispano-Americana de Electricidad (CHADE) y fue dirigido por el norteamericano de descendencia alemana Dannie Heinemann (1872-1962), director de la Société Financière de Transports et d'Entreprises Industrielles (Sofina) en Bruselas, la cual por razones legales tenía su sede en esta ciudad belga. Dado que la CTEV de Valparaíso era propiedad 100 por ciento de la DUEG/CATE desde 1906, ella también pasó al portafolio de la nueva CHADE en 1920, pero ya en 1923 fue comprada por la nueva Chilectra inglesa que en esos momentos, y con mucha ilusión como dijimos, ampliaba de manera impresionante sus áreas de operación en el centro de Chile. Dannie Heineman, el personaje clave de la conversión de la DUEG/CATE en la CHADE, debía su puesto de director de la Sofina a la AEG la cual lo había instalado en esta función en 1905 cuando aún controlaba a la Sofina. Heineman iba a dirigir la Sofina durante 50 años, y la CHADE tenía un papel clave para su éxito. De a poco, la Sofina se convirtió en el nuevo "nodo" dentro de una "red confusa" de dimensión mundial. "Paso a paso", escribe el historiador de la casa Siemens con el nombre algo desconcertador de

85 Castillo 1994, 43; Couyoumdjian 1986, 221-226; Municipalidad de Santiago 1919.

(C) Labor \& Engenho, Campinas [SP] Brasil, v.11, n.4, p.446-476, out./dez. 2017. 
Georg Siemens, Heineman transformó a la Sofina en "el mayor holding de operaciones eléctricas en Europa, tal vez incluso en el mundo entero" 86.

Tres meses antes de la liquidación de la DUEG/CATE, ocurrió un incidente excepcional en Valparaíso: el 10 de marzo de 1920, ciudadanos enojados incendiaron los tranvías y destruyeron gran parte de la flota. Una de sus principales críticas, que ya se había discutido una y otra vez en los periódicos durante los años anteriores, fue que la empresa operadora alemana no se hubiera preocupado lo suficientemente bien del mantenimiento de las infraestructuras eléctricas ni de los carros de los tranvías cuyas condiciones se habían ido empeorando visiblemente a lo largo del tiempo. Además, la compañía había roto varias de las promesas hechas al municipio en el contrato renovado en 1910, en el cual se había comprometido, por ejemplo, a construir tres nuevas líneas de tranvía en los cerros. Aunque en ambos casos la crítica era, de hecho, muy adecuada, hay que recordar que durante la guerra fue simplemente imposible para la empresa alemana realizar estas actividades porque el bloqueo económico de los ingleses impedía cualquier transporte de suministro y de materiales procedentes de Alemania, incluso restringiendo de manera muy considerable la comunicación entre los empleados de las casas matrices en Berlín y las filiales en Chile87.

Así es que en el año 1920, el Imperio Alemán había perdido, al menos temporalmente, su carrera en el mercado mundial, la cual había comenzado con la unificación de la nación en 1871 y la incipiente revolución eléctrica a partir de 1880, y mediante la cual desafió, en concurrencia permanente con los Estados Unidos, a la potencia mundial hegemónica de aquel momento, el Reino Unido. A largo plazo, sin embargo, se puede constatar que las estrategias sutiles de dominación económica puestas en marcha en este periodo por las empresas e institutos financieros alemanes se han establecido y funcionan hasta el día de hoy de manera eficaz como una especie de colonialismo económico no-territorial e imperialista. En el desarrollo altamente capitalista, que iba a determinar el curso de nuestro mundo a lo largo del siglo XX y que sigue caracterizando nuestro presente, la nueva tecnología eléctrica, intensiva en capital y de gran escala, tuvo una influencia decisiva. Facilitó además una nueva percepción de Alemania como 'país de los milagros tecnológicos' y el surgimiento de la marca Made in Germany muy exitosa que sigue jugando un rol económico y de imagen fundamental para la nación exportadora en el presente. La historia, entonces, no ha terminado todavía...

\section{Referencias}

Albrecht, H. (2012). Alfred Beit - The Hamburg Diamond King. Hamburgo: Hamburg University Press, 148 p. Financiado por The Beit Trust, traducido al inglés por Christopher Watson, BA, Hamburgo y Neil Munro, Londres [primero publicado en alemán: Alfred Beit - Hamburger und Diamantenkönig, Hamburg University Press 2011, 152 p.]

Allgemeine Elektricitäts-Gesellschaft (1900). Elektrische Strassenbahnen - Electric Tramways - Tramways Electriques. Berlín: AEG, 398 p. [SDTB, Archivo AEG, sig. III.2 01465].

Armengol Ferrer, F. (2013). L'experiència de l'electrificació del transport a Barcelona (pp. 179-207). Barcelona Quaderns d'Història, (19). L'Electrificació de Barcelona, 1881-1935.

Brasilianische Bank für Deutschland (1912). Brasilianische Bank für Deutschland. Hamburg - Brasilien, 1888-1912. Hamburgo: Brasilianische Bank für Deutschland, 39 p.

Capel, H. (ed.) (1994). Las Tres Chimeneas. Implantación industrial, cambio tecnológico y transformación de un espacio urbano barcelonés. Barcelona: FECSA, 3 vols., 222 y 226 p.

Castillo, S. (1994). Historia de Chilectra S.A. Los primeros 50 años. Santiago de Chile: Chilectra, Dirección de Planificación, 212 p. [versión publicada].

\footnotetext{
86 Feldman 1995, 201-203; Hausman et al. 2008, 100, 134-135, 151, 187; Siemens 1961, 193-194

87 Ugarte Yávar 1910, 82; Morrison 2013, 9, 45-47; Flores 2000, 107
} 
Sociedad Chilena de Tranvías y Alumbrado Eléctricos (1898). Memorial presentado a la Ilustre Municipalidad por los contratistas de la tracción i alumbrado eléctricos de Santiago en 7 de marzo de 1898. Santiago de Chile: Establecimiento Poligráfico Roma, 16 p.

Chilian Electric Tramway and Light Company Limited (1899). Documentos. Santiago de Chile: Impr. Litografía i Encuadernación Barcelona, 547 p.

Chilian Electric Tramway and Light Company Limited (1914). Recopilación de los bases, antecedentes i contratos con la Ilustre Municipalidad de Santiago para los tranvías i concesión para alumbrado eléctricos de Santiago. Santiago de Chile: Chilian Electric Tramway and Light Company Limited, 158 p.

Compañía Alemana Transatlántica de Electricidad (1916). La Compañia Alemana Transatlántica de Electricidad en Santiago: a los señores representantes de las Empresas de Electricidad en Chile en conmemoración de la $1 a$. Conferencia celebrada en Santiago, el 15 de marzo de 1916. Santiago de Chile: CATE, 18 p. [Biblioteca Nacional de Chile, síg. 427850 (microformatos)].

Couyoumdjian, J. R. (1986). Chile y Gran Bretaña durante la primera Guerra Mundial y la postguerra, 1914-1921. Santiago de Chile: Andrés Bello, Universidad Católica de Chile, impresión: Salesianos, 340 p.

Dame, T. (2011). Elektropolis Berlin: Die Energie der Großstadt. Bauprogramme und Aushandlungsprozesse zur öffentlichen Stromversorgung in Berlin. Berlín: Mann (Gebr.), 611 p.

Dávila Izquierdo, 0. (1901). La Empresa de Tracción Y Alumbrado Eléctricos de Santiago. Memoria premiada en el certamen anual al que concurren a la Universidad del Estado los alumnos del curso de Economía Política del señor Don Pedro Luis González. Santiago de Chile: Imprenta Nacional, 103 p.

Deulofeu Fuller, G. (1999). Central Hidroeléctrica El Sauce. Legado Patrimonial de la Industria de Valparaíso. Tesis de título, Universidad Marítima de Chile, Escuela de Arquitectura, Valparaíso, 107 p.

Deutsche Ueberseeische Bank (1936). Deutsche Überseeische Bank, 1886-1936. Aus Anlass des 50-jährigen Bestehens der Deutschen Ueberseeischen Bank ihren Mitarbeitern und Freunden gewidmet. Publicación realizada con ocasión del $50^{\circ}$ aniversario del banco. Berlín: DUB.

Feldman, G. D. (1995). Die Deutsche Bank vom Ersten Weltkrieg bis zur Wirtschaftskrise, 1914-1933 (pp. 137-314). In L. Gall et al. Die Deutsche Bank 1870-1995. Múnich: C. H. Beck.

Figueroa, P. P. (1888). Diccionario Biográfico General de Chile (1550-1887). Santiago de Chile: Imprenta Victoria de H. Izquierdo y Cía., $2^{a}$ ed., 653 p.

Flores Farías, S. (2000). Chilquinta Energia. Cien años de luz: una mirada histórica sobre la Quinta Región de Valparaíso. Santiago de Chile: Impresora y Editora Ograma S.A., 147 p.

Fuentes Pradenas, P. (2014). Central Hidroeléctrica El Sauce: Innovación y Vanguardia para el Desarrollo Industrial y Urbano de Valparaíso (pp. 82-104). El Boletín Histórico de la Provincia de Marga-Marga, Año III, $\mathrm{N}^{\circ}$ 9, Primer Trimestre, Departamento de Publicaciones de la Sociedad de Historia y Geografía de la Provincia de Marga-Marga.

Gall, L. et al. (1995). Die Deutsche Bank 1870-1995. Múnich: C. H. Beck, 1015 p.

Gall, L. (1995). Die Deutsche Bank von ihrer Gründung bis zum ersten Weltkrieg, 1870-1914 (pp. 1-135). In L. Gall et al.. Die Deutsche Bank 1870-1995. Múnich: C. H. Beck.

Gwinner, A. (1992). Lebenserinnerungen. Frankfurt am Main: Fritz Knapp Verlag [escrito en 1926, primera edición por Manfred Pohl en 1975], 199 p.

Hausman, W. J.; HERTNER, Peter; WILKINS, Mira (2008). Global electrification: multinational enterprise and international finance in the history of light and power, 1878-2007. Cambridge: Cambridge University Press, $487 \mathrm{p}$.

(C) Labor \& Engenho, Campinas [SP] Brasil, v.11, n.4, p.446-476, out./dez. 2017. 
Hertner, P. (2013). Foreign direct investment in Chile and local public utilities: electric tramways and the first electrical power plants in Santiago de Chile and Valparaiso between 1898 and 1920 (pp. 89-100). In Asociación Chilena de Historia Económica [ACHHE] (ed.). Chile y América en su Historia Económica. Valparaíso: El Mercurio de Valparaíso Impresores.

Jacob-Wendler, G. (1982). Deutsche Elektroindustrie in Lateinamerika: Siemens und AEG 1890-1914. Stuttgart: Klett-Cotta, 376 p.

Krebs, C., \& Pommerenke, G. (1913). Deutscher Handel und Deutsche Schifffahrt in Chile (pp. 72-87). In Deutscher Wissenschaftlicher Verein (ed.). Deutsche Arbeit in Chile, Publicación realizada con ocasión del centenario de la República de Chile, Vol. II, Santiago de Chile: Imprenta Universitaria.

Loscertales, J. (2002). Deutsche Investitionen in Spanien 1870-1920. Stuttgart: Franz Steiner Verlag, 344 p.

Lynch L., Alfredo (1908). Descripción de las obras hidroeléctricas que la Compañía de Tranvía Eléctricos de Valparaíso posee en Peñuelas i en especial los nuevos trabajos cuyo objeto es aumentar su poder (pp. 352-358). Anales del Instituto de Ingenieros de Chile, (8) Año VIII, agosto.

McSweeney, A. (2015). Arthur von Gwinner und die Alhambra-Kuppel (pp. 89-102). In J. Gonnella, \& J. Kröger (eds.). Wie die Islamische Kunst nach Berlin kam. Der Sammler und Museumsdirektor Friedrich Sarre. Berlín: Dietrich Reimer Verlag.

Morrison, A. (2013). Los tranvías de Chile 1858-1978. Santiago de Chile: Librería Editorial Ricaaventura EIRL, 2 ${ }^{\mathrm{a}}$ ed, $145 \mathrm{p}$.

Müller, M. L., \& Schinckel, M. H. von (2005). Neue Deutsche Biographie 22 (pp. 784-785). Recuperable en: http://www.deutsche-biographie.de/pnd118755080.html

Municipalidad de Santiago (1890-1911). Boletín de Actas y Documentos de la Ilustre Municipalidad de Santiago. Santiago: La Municipalidad, 25 vols. [incluye las actas de las sesiones municipales 1892-1910].

Municipalidad de Santiago (1919). Internacionalismo del Capital: Consorcio Inglés y Alemán durante la Guerra - La Legación Británica y la Administración Alemana de la Chilian Electric Tramway \& Light Co. Ltd. Santiago de Chile: Imprenta y Librería Artes y Letras, 223 p.

Municipalidad de Valparaíso (1902). Recopilación de leyes, ordenanzas, reglamentos y demás disposiciones vijentes en el territorio municipal de Valparaíso. Valparaíso: Babra, 1109 p. [incluye las Bases para el Alumbrado eléctrico (pp. 995-998) y la tracción eléctrica (pp. 998-1010) acordadas en sesión municipal extraordinaria del 17.1.1902].

Municipalidad de Valparaíso (1875-1908). Documentos Municipales y Administrativos de Valparaíso. Valparaíso: Imprenta del Mercurio, 11 vols. [incluye las actas de las sesiones municipales 7.8.1872-19.4.1900].

Nahm, G. (1997). Las inversiones extranjeras y la transferencia de tecnología entre Europa y América Latina: El ejemplo de las grandes compañías eléctricas alemanas en Argentina. Scripta Nova, $\mathrm{n}^{\circ} 1,1$ de marzo. Recuperable en: http:/www.ub.edu/geocrit/sn-1.htm

Pohl, Manfred (1988). Emil Rathenau und die AEG. Mainz: v. Hase \& Koehler Verlag, 285 p.

Reitmayer, M. (1999). Bankiers im Kaiserreich: Sozialprofil und Habitus der deutschen Hochfinanz. Göttingen: Vandenhoeck \& Ruprecht, 428 p.

Roca i Albert, Joan (2012). Estratègies d'inserció i interconnexió de Barcelona com a metròpoli moderna. Barcelona Quaderns d'Història, 18. Presència i lligams territorials de Barcelona. Vint segles de vida urbana.

Seidenzahl, F. (1984). Die Anfänge der Deutsch-Ueberseeischen Elektricitäts-Gesellschaft (pp. 277-322). In M. Pohl (ed.). Beiträge zu Wirtschafts und Währungsfragen und zur Bankgeschichte. Mainz (1-20), [primera publicación en: Veit, 0. (1968). Elemente der Goldwährung in der neuen Währungsordnung. Frankfurt am Main]. 
Siemens, G. (1961). Der Weg der Elektrotechnik: Geschichte des Hauses Siemens (2.ed., 2 vols., 387 y 391 p.). Freiburg/Múnich: Karl Alber.

Steiner, M. (2013). Tracing the Invisible - Electropolis Berlin (pp. 230-240). Selected Papers of the XVth International Congress of the International Committee for the Conservation of the Industrial Heritage, Taipei: Chung Yuan Christian University.

Tornero, C. (ed.) (s.d.). Chile: descripción física, política, social, industrial y comercial de la República de Chile. Santiago de Chile: Librería C. Tornero y Compañía, 312 p.

Trevelyan, R. (2013). Grand Dukes and Diamonds. The Wernhers of Luton Hoo. Londres: Faber and Faber, edición de bolsillo, 528 p.

Ugarte Yávar, J. D. (1910). Valparaíso 1536-1910. Recopilación histórica, comercial y social. Valparaíso: Imprenta Minerva, $398 \mathrm{p}$.

Wilkins, M. (1970). The Emergence of Multinational Enterprise: American Business Abroad from the Colonial Era to 1914. Cambridge, MA: Harvard University Press.

Robinson Wright, M. (1904). The Republic of Chile - the growth, resources, and industrial conditions of a great nation. Philadelphia: G. Barrie \& sons y London, Paris: C. D. Cazenove \& son, 450 p. 